\title{
Ares I-X In-Flight Modal Identification
}

\author{
Theodore J. Bartkowicz ${ }^{1}$ \\ The Boeing Company - Space Exploration Division, Houston, TX, 77059, USA \\ George H. James III ${ }^{2}$ \\ NASA Johnson Space Center, Houston, Houston, TX, 77058, USA
}

\begin{abstract}
Operational modal analysis is a procedure that allows the extraction of modal parameters of a structure in its operating environment. It is based on the idealized premise that input to the structure is white noise. In some cases, when free decay responses are corrupted by unmeasured random disturbances, the response data can be processed into cross-correlation functions that approximate free decay responses. Modal parameters can be computed from these functions by time domain identification methods such as the Eigenvalue Realization Algorithm (ERA). The extracted modal parameters have the same characteristics as impulse response functions of the original system. Operational modal analysis is performed on Ares I-X in-flight data. Since the dynamic system is not stationary due to propellant mass loss, modal identification is only possible by analyzing the system as a series of linearized models over short periods of time via a sliding time-window of short time intervals. A time-domain zooming technique was also employed to enhance the modal parameter extraction. Results of this study demonstrate that free-decay time domain modal identification methods can be successfully employed for in-flight launch vehicle modal extraction.
\end{abstract}

\section{Nomenclature}

$\begin{array}{ll}C & =\text { damping matrix } \\ K & =\text { stiffness matrix } \\ M & =\text { mass matrix } \\ \mathbf{x} & =\text { vector of } \mathrm{x} \\ \mathbf{f} & =\text { force vector } \\ \phi_{\mathrm{A}} & =\text { mode shape } \mathrm{A} \\ \mathrm{T} & =\text { period }\end{array}$

\section{Introduction}

$\mathrm{T}$ He Ares I-X was a pathfinder vehicle concept developed NASA to demonstrate a new class of Ares I launch vehicles. The 327-foot Ares I-X flight test vehicle (FTV) consisted of 4-segment reusable, Space Shuttleheritage solid rocket motor with mass simulators for the $5^{\text {th }}$ segment, upper stage (US), and combined crew module (CM)/launch abort system (LAS) as shown in Figure 1. The FTV was assembled at the Vehicle Assembly Building (VAB) at NASA's Kennedy Space Center (KSC). It successfully lifted off on October 28, 2009 at 11:30am Eastern Daylight Time (EDT) from KSC for a two-minute powered flight. The flight test lasted about six minutes from its launch until splashdown of the rocket's booster stage nearly 150 miles downrange. ${ }^{1}$ Primary Ares I-X objectives included: demonstrate control of a dynamically similar vehicle using control algorithms similar to those used for Ares I, perform a nominal in-flight separation/staging event between an Ares I-similar first stage (FS) and a representative US, and demonstrate assembly and recovery of an Ares I-like FS at KSC. ${ }^{2}$ In addition, NASA engineers will analyze data to better understand the effectiveness of first stage separation motors and better

\footnotetext{
${ }^{1}$ Associate Technical Fellow, Structures, Mechanics \& Element Integration, 13100 Space Center Blvd, M/S: HB420, Houston, TX, 77059, Senior AIAA Member.

2 Aerospace Engineer, Loads and Structural Dynamics Branch, 2101 NASA Parkway, M/S: ES6, Houston, TX, 77059, AIAA Member.
} 
understand the flight environments on the vehicle during ascent. Data would also be used to ensure the rocket design is safe and stable in flight prior to putting a crew on a similar vehicle into orbit.

Pre-flight structural loads assessments and flight control algorithms were developed based on finite element model (FEM) predictions. Calibration of the FEM was completed from two partial stack modal tests and a full stack modal test of the FTV mounted ("cantilevered") to the Mobile Launch Platform. ${ }^{3-4}$ For the cantilevered full stack modal test, target modes were the first four bending model mode pairs based on flight control requirements. These modal test configurations could not capture several factors that are present in in-flight modal response such as freefree boundary conditions, aerodynamic loading, thrust forces, pressurization, and mass changes due to the fuel burning. Therefore, further verification of FEM predictions with in-flight data was desired.

Since the force input was unknown, the in-flight random response data was processed into cross-correlation functions that approximate free decay responses. A time-domain, free decay modal analysis method based on the Eigenvalue Realization Algorithm (ERA) ${ }^{5}$ and a time-domain zooming method were selected to extract modal parameters from these functions. Since the FTV constantly changes due to propellant mass loss, a sliding-time window was applied to characterize a series of 5-second (s)-long data windows at 2.5-s intervals throughout 120 seconds of first stage burn. The modal parameters extracted from in-flight data were compared to FEM predictions. This paper describes the flight instrumentation used in the assessment, the data processing, the random data processing approach, comparisons between in-flight and predicted modal parameters, and set of lessons-learned from the analysis.

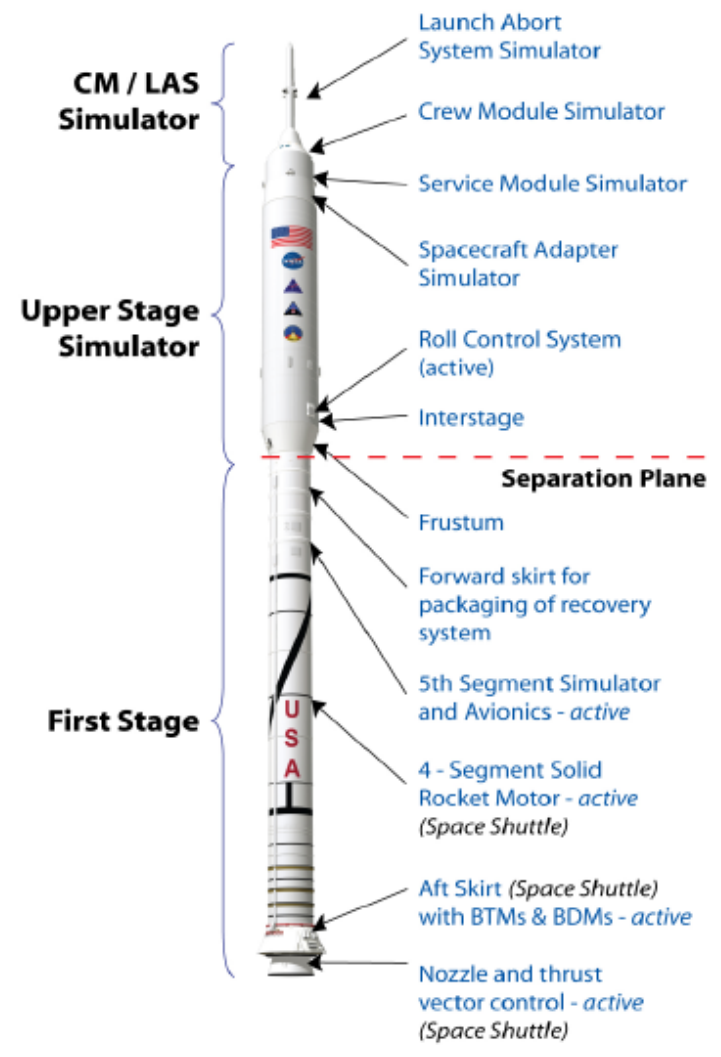

Figure 1. Ares I-X Flight Test Vehicle (illustration courtesy of NASA ${ }^{1}$ )

\section{Flight Instrumentation and Initial data Processing}

The instrumentation used in the initial data extraction consisted of fifty-eight (58) of the low frequency accelerometers (see Figure 2) from the Ares I-X Development Flight Instrumentation (DFI) measurement list. ${ }^{6}$ The selected accelerometers were all Micro-Electro-Mechanical Systems (MEMS) type high sensitivity DC accelerometers that were sampled at approximately $325.5 \mathrm{Hertz}(\mathrm{Hz})$. Accelerometers below the frustum had a $100 \mathrm{~g}$ accelerometer range and frequency range of 0 to $1.5 \mathrm{kHz}$. All other accelerometers had a $30 \mathrm{~g}$ acceleration and frequency range of 0 to $1.0 \mathrm{kHz} .^{7}$ 

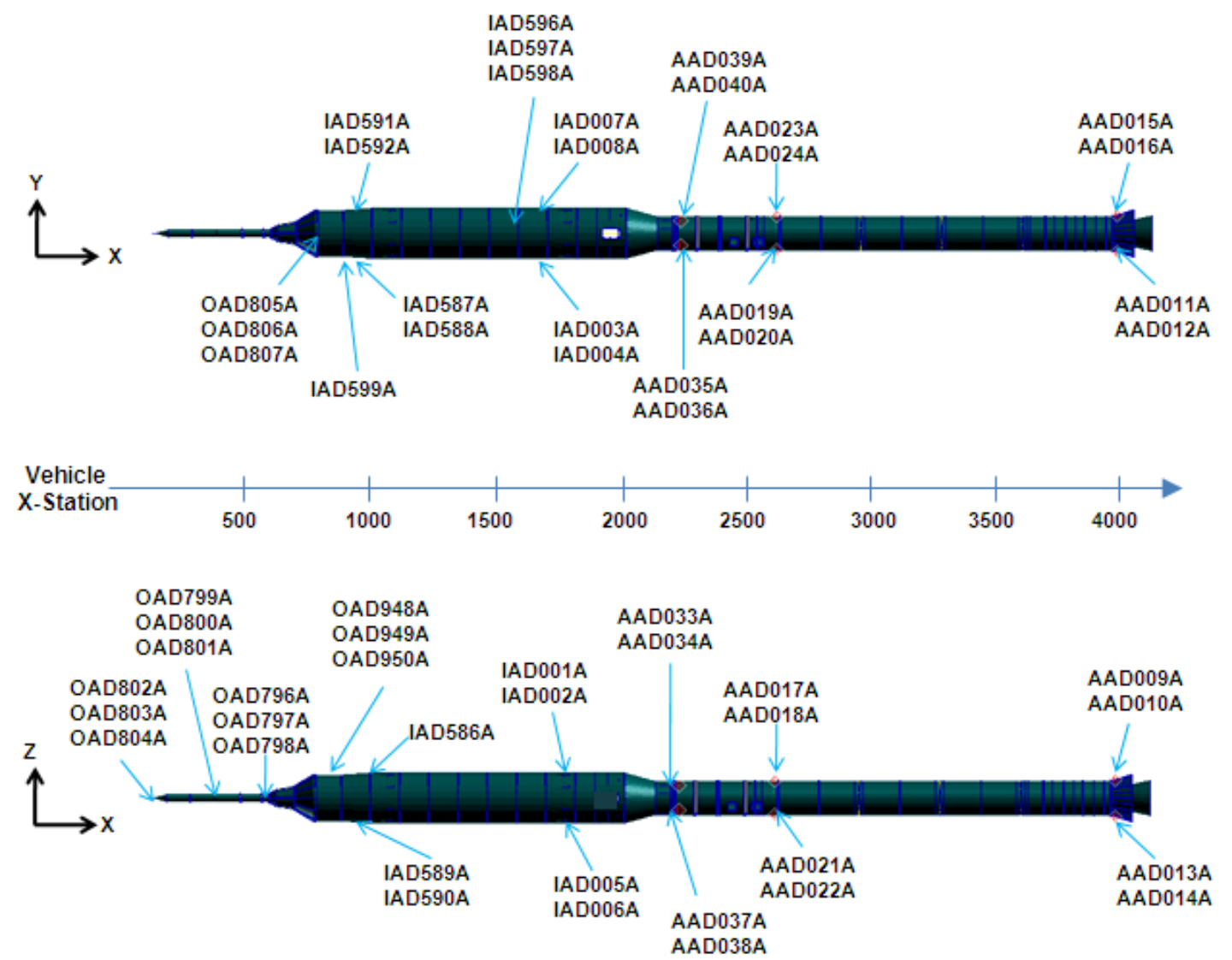

Figure 2. Ares I-X DFI Accelerometer Locations

Flight data were acquired from a database on the Ares Engineering and Operations Network (AEON) server maintained by the Huntsville Operations Support Center (HOSC). Data was downloaded with an initial $(\mathrm{T}=0)$ time reference defined as 2009:301:15:29:30.000. Data from liftoff through just prior to stage separation were extracted for each of the channels. It was observed that the flight data was not "time-synched" among all channels due to an acquisition phase shift between groups of accelerometers. It appeared that acquisition time was grouped based on the location of vehicle as confirmed by NASA Langley (LaRC). ${ }^{7}$ Since the analysis techniques require all data to be synchronized, all data was manually shifted to a nominal time vector based on accelerometer channel AAD009A, with a maximum shift of 0.00278 seconds. Manual time synchronization produces a phase error in the modal parameter extraction and the error increases linearly with modal frequency. Since the frequency of interest is low (target modes less than $10 \mathrm{~Hz}$ ), the phase error is not significant.

The time history data were resampled at $500 \mathrm{~Hz}$. Figure 3 shows sample accelerometer flight measurements, which are presented in units of "normalized response" for amplitude and "\% of early burn" for time to avoid any issues with current government-imposed data restrictions. Since the flight data included DC bias, the data were detrended with piecewise (break points every 2.5 seconds) linear interpolation to remove the DC bias. In addition, the data were also filtered with a $0.5-40 \mathrm{~Hz}$ bandpass filter to remove high frequency content. Accelerometer data were first examined for consistency and polarity. Time history plots identified data anomalies such as bad channels due to either data dropouts, inconsistent local responses or poor data resolution due to a high max range setting and 12-bit analog-to-digital (A/D) data acquisition. Accelerometer data were examined for consistency and polarity. Polarity of axial measurements was verified in the DC response at liftoff and ascent. Polarity verification of lateral measurements was provided by NASA-LaRC. Spectrograms were also developed to evaluate the frequency content of the vehicle response. The spectrograms quickly identified mislabeled axial and lateral sensor channels. Sample plots of axial and lateral vehicle measurements are provided in Figure 4 and Figure 5, respectively. Any anomalous data channels were removed in further analysis. 

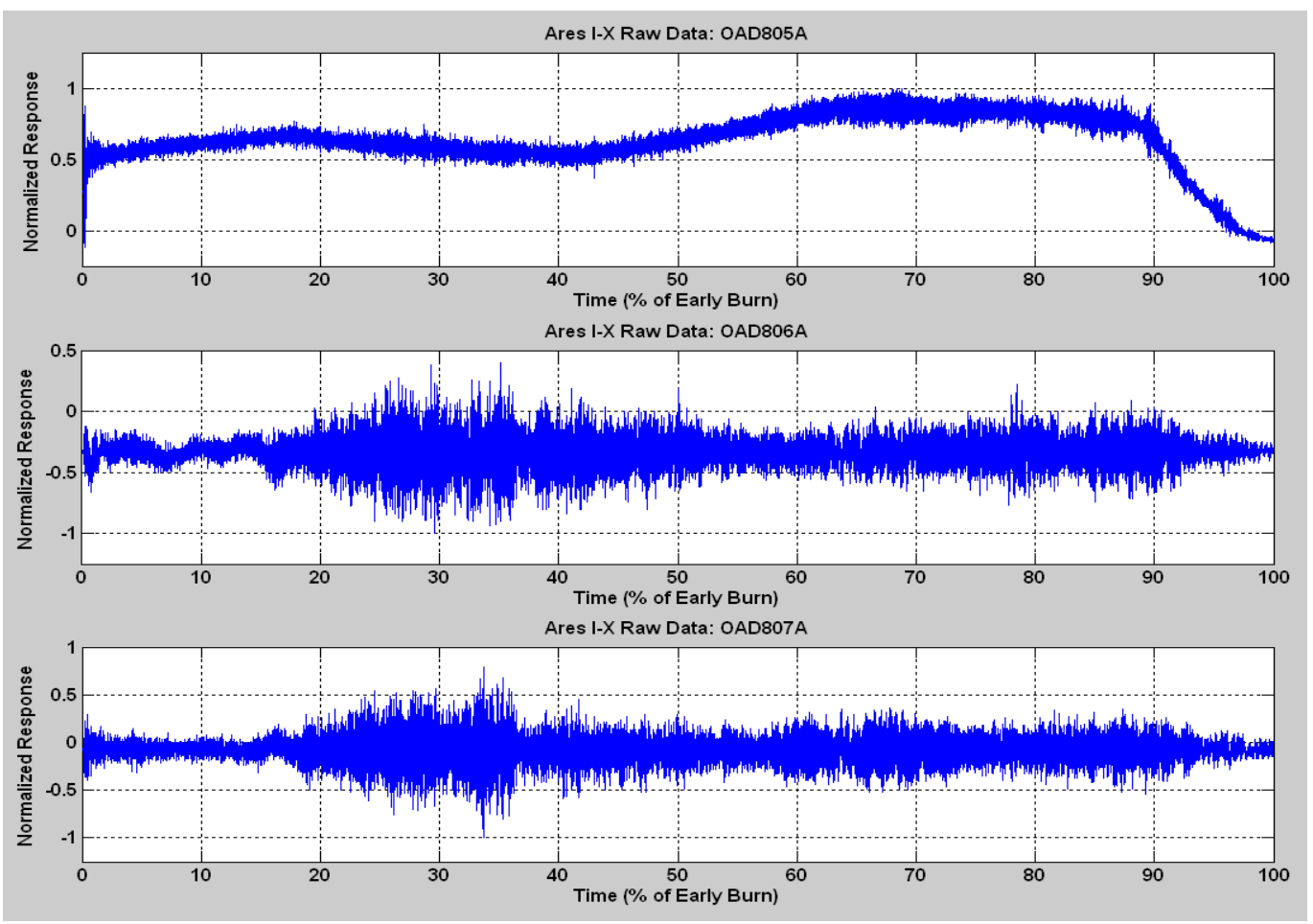

Figure 3. Ares I-X Flight Data Time Histories
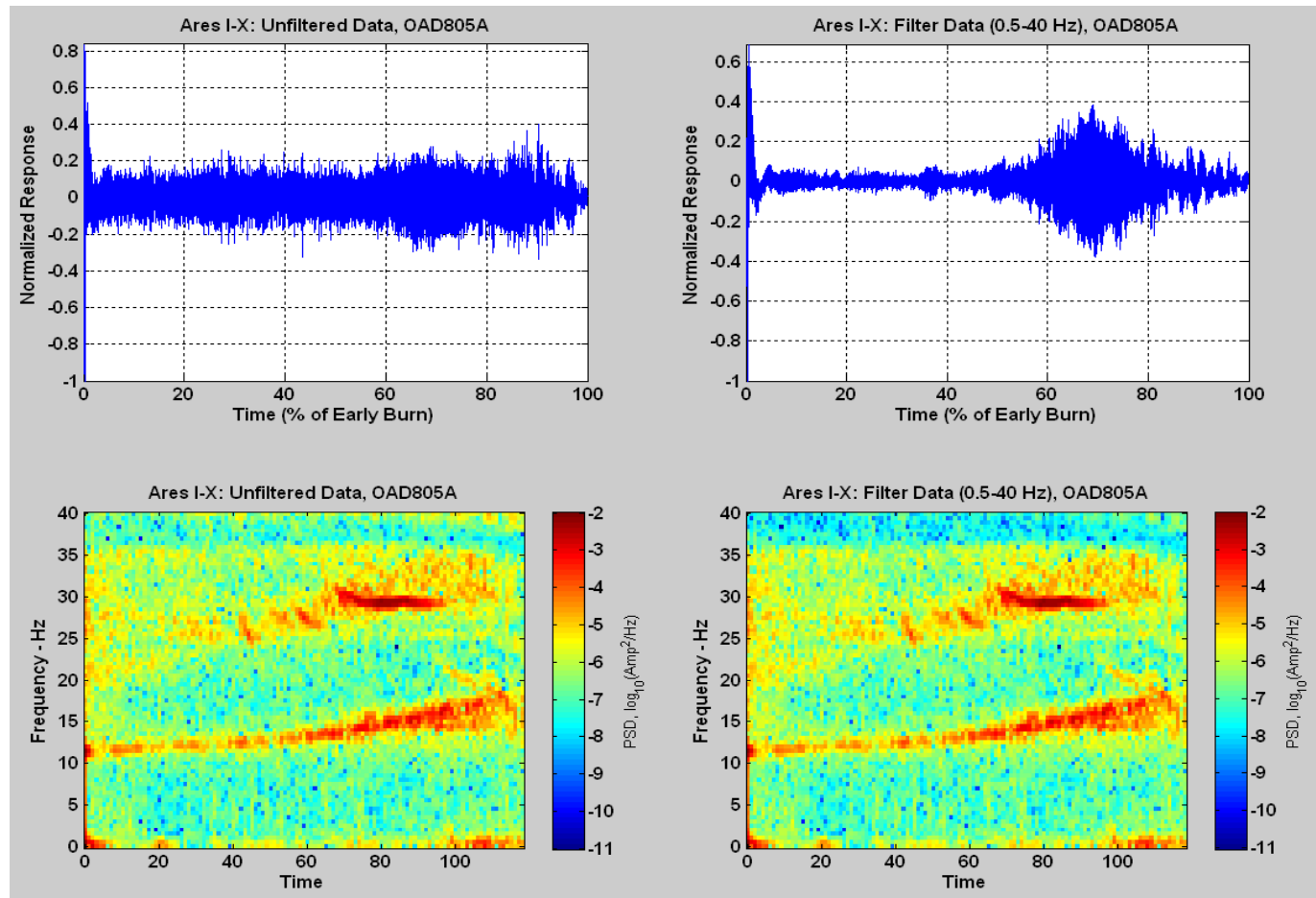

Figure 4. Detrended and Filtered Flight Data: Axial Measurement 

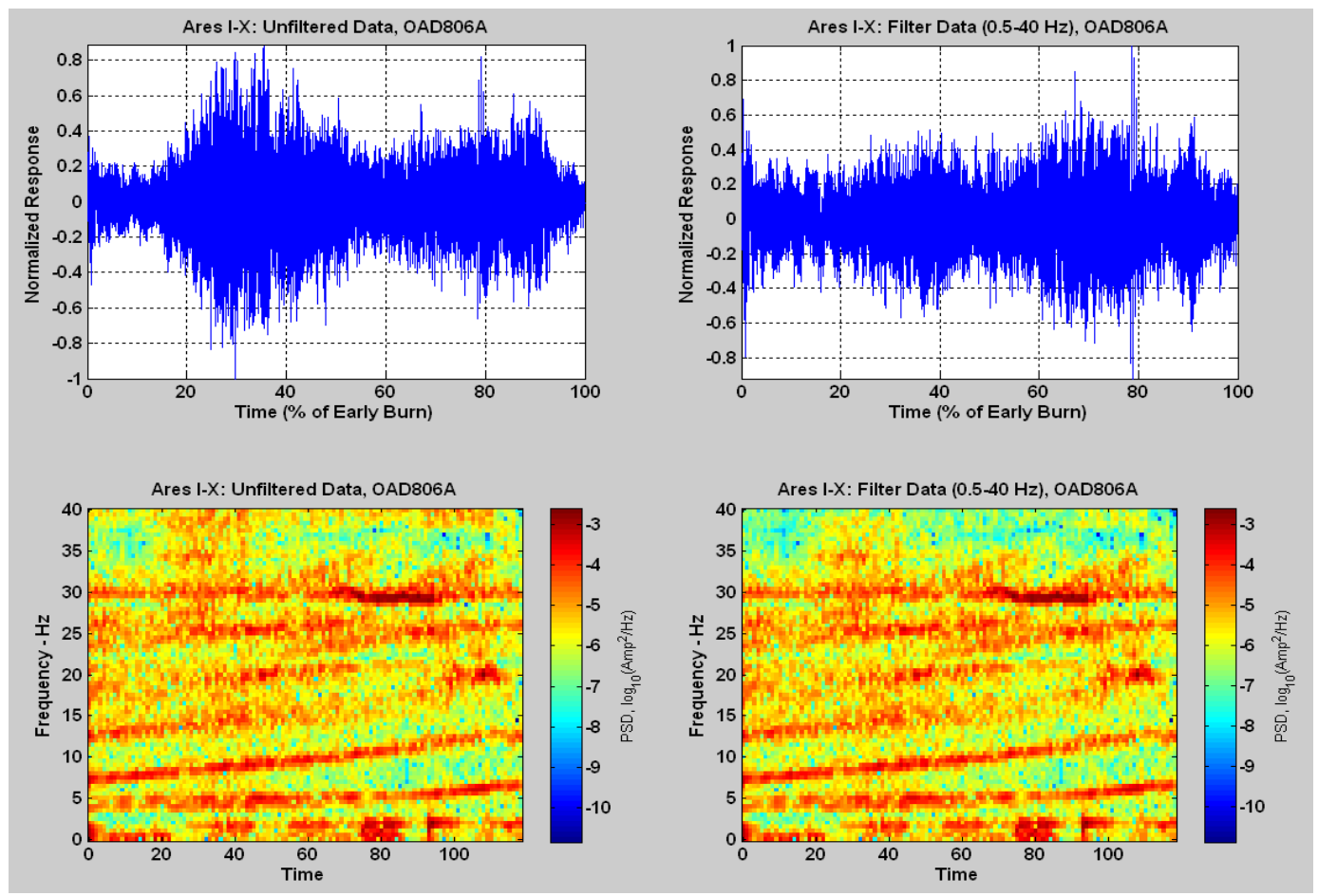

Figure 5. Detrended and Filtered Flight Data: Lateral Measurement

\section{Free Decay Modal Identification Methods Development}

In conventional modal analysis, impulse response functions calculated from inverse Fourier transforms of frequency response functions (FRFs) have been widely used with time-domain modal identification algorithms. ${ }^{8-9}$ This approach is called a forced response technique since the FRF is determined using both input and output measurements from the forced response testing of structures. Indirect free-decay data obtained in this manner is relatively noise free and absent of significant nonlinearities due to the large number of averages employed to obtain high-quality FRFs.

In free-decay modal analysis, the modal identification algorithm is applied directly to free-decay responses of the structure. A special modal identification method ${ }^{10}$ was employed, which has been developed for large space structures. It is a time-domain, free-decay method based on the ERA ${ }^{5}$ and a time-domain zooming method. This method does not require input force measurements and characterizes nonlinearities by extracting modal parameters with a series of linearized models over short periods of the free decay data rather than using the entire period, which is necessary in a forced response technique.

\section{A. Random Data Processing}

Ares I-X flight data are measured forced responses. FRFs are not available because the force input is unknown. In situations where free-decay responses are corrupted by unmeasured random disturbances, the response data can be processed into cross-correlation functions that approximate free-decay responses of a structure. ${ }^{10}$ Consider a general n-Degree of Freedom (DOF), linear time-invariant dynamic system with the equations of motion written in the form:

$$
M \ddot{\mathbf{x}}(t+\tau)+C \dot{\mathbf{x}}(t+\tau)+K \mathbf{x}(t+\tau)=\mathbf{f}(t+\tau)
$$

Premultiplying Eq. (1) by $\mathrm{x}_{\mathrm{i}}(\mathrm{t})$, a reference coordinate, integrating from 0 to $\mathrm{T}$, and taking the limit as $\mathrm{T}$ tends to infinity: 


$$
\begin{aligned}
& \lim _{T \rightarrow \infty} \frac{1}{T} \int_{0}^{T} x_{i}(t) M \ddot{\mathbf{x}}(t+\tau) d t+\lim _{T \rightarrow \infty} \frac{1}{T} \int_{0}^{T} x_{i}(t) C \dot{\mathbf{x}}(t+\tau) d t+ \\
& \lim _{T \rightarrow \infty} \frac{1}{T} \int_{0}^{T} x_{i}(t) K \mathbf{x}(t+\tau) d t=\lim _{T \rightarrow \infty} \frac{1}{T} \int_{0}^{T} x_{i}(t) \mathbf{f}(t+\tau) d t
\end{aligned}
$$

Differentiation and integration can be interchanged if the integrals in Eq. (2) converge uniformly:

$$
\begin{aligned}
& M \frac{d^{2}}{d \tau^{2}} \lim _{T \rightarrow \infty} \frac{1}{T} \int_{0}^{T} x_{i}(t) \mathbf{x}(t+\tau) d t+C \frac{d}{d \tau} \lim _{T \rightarrow \infty} \frac{1}{T} \int_{0}^{T} x_{i}(t) C \mathbf{x}(t+\tau) d t+ \\
& K \lim _{T \rightarrow \infty} \frac{1}{T} \int_{0}^{T} x_{i}(t) K \mathbf{x}(t+\tau) d t=\lim _{T \rightarrow \infty} \frac{1}{T} \int_{0}^{T} x_{i}(t) \mathbf{f}(t+\tau) d t
\end{aligned}
$$

Equation (3) can be written is the simplified form:

$$
M \ddot{\mathbf{r}}(\tau)+C \dot{\mathbf{r}}(\tau)+\operatorname{Kr}(\tau)=\mathbf{h}(\tau)
$$

where $\mathbf{r ( ~ ) ~ a n d ~} \mathbf{h}$ ( ) are cross-correlation functions. ${ }^{11}$

$$
\begin{aligned}
& \mathbf{r}(\tau) \equiv \lim _{T \rightarrow \infty} \frac{1}{T} \int_{0}^{T} x_{i}(t) \mathbf{x}(t+\tau) d t \\
& \mathbf{h}(\tau) \equiv \lim _{T \rightarrow \infty} \frac{1}{T} \int_{0}^{T} x_{i}(t) \mathbf{f}(t+\tau) d t
\end{aligned}
$$

If $\mathbf{f}($ ) is white noise, then by definition

$$
\mathbf{h}(\tau)=0
$$

Therefore, Eq. (4) becomes the homogenous equations

$$
M \ddot{\mathbf{r}}(\tau)+C \dot{\mathbf{r}}(\tau)+\operatorname{Kr}(\tau)=0
$$

Multiple data channels can be processed into auto/cross-correlation functions by selecting one channel as a reference, $\mathrm{x}_{\mathrm{i}}(\mathrm{t})$. The modal identification algorithm is applied to the cross-correlation functions, $\mathbf{r}(\mathrm{)})$. The modal identification algorithm is applied to the cross-correlation functions. As shown in Eq. (7), these functions represent free-decay responses from initial conditions, $\mathbf{r}(0)$ and the modal parameters have the same characteristics as impulse response functions of the original system. ${ }^{12}$ In cases when $\mathbf{f}(\mathrm{t}+)$ is not white noise and $\mathbf{h}() \neq 0$, usable data can be obtained if the magnitude of $\mathbf{h}(\mathrm{)})$ is small relative to the responses of initial conditions, $\mathbf{r}(0)$.

\section{B. Cross-Correlation Functions}

The cross-correlation random data processing approach described above was applied to the Ares I-X accelerometer flight data in an attempt to identify modes excited by unmeasured random disturbance. Since the Ares I-X vehicle dynamics change during ascent due to propellant mass loss and center of gravity shift due to fuel burning, modal identification is possible only if response data over relatively short time intervals is used. The 
analysis was begun by pre-filtering the response data using a bandpass Finite Impulse Response (FIR) filter to eliminate aliasing and bias. A sliding time window technique was applied to characterize the system in a series of 5s-long data windows at 2.5-s intervals throughout the ascent period. It was assumed that the system remained sufficiently constant for a 5-s time span to allow modal identification.

Auto/cross-correlation functions were generated for these windows. Multiple sets of cross-correlation functions were generated using different accelerometer response channels as the reference channel. The intent was to determine the best channel which produced cross-correlation functions that most resembled free-decay responses. It was determined that reference channel AAD009A (see Figure 2) served as the best reference channel for this vehicle

To utilize the time-zooming technique, the detrended data was filtered by different bandpass filters $(0.05-7.5 \mathrm{~Hz}$, 5.0-20 Hz and 17.5-35 Hz) to emphasize different frequencies. This process is comparable to a frequency-domain zooming technique used in the traditional modal analysis methods. It is again noted that the selected modal analysis process is based on the free-decay method and applied to the free-decay portion of the data sets, which in this case are the cross-correlation functions (see Figure 6). The ERA modal extraction is applied to a series of crosscorrelation functions by using different data record lengths from 0.5 to 3.5 seconds. This is performed to extract the most consistent modal content in the data. The whole process described herein has been implemented in a Boeing proprietary MATLAB ${ }^{\mathrm{TM}}$ based Graphical User Interface (GUI) software entitled "Boeing Test Analysis Correlation Solutions” (BTACS). To further enhance the modal parameter extraction, data sets were separated into a set of axial measurements and lateral measurements and the ERA was applied to each set for identifying axial and bending modes, respectively. One important point is the "beating" at the higher time lags in the correlation functions. Other analysts ${ }^{13}$ have identified the same "beating" phenomena, which provide an additional challenge to estimate modal damping.
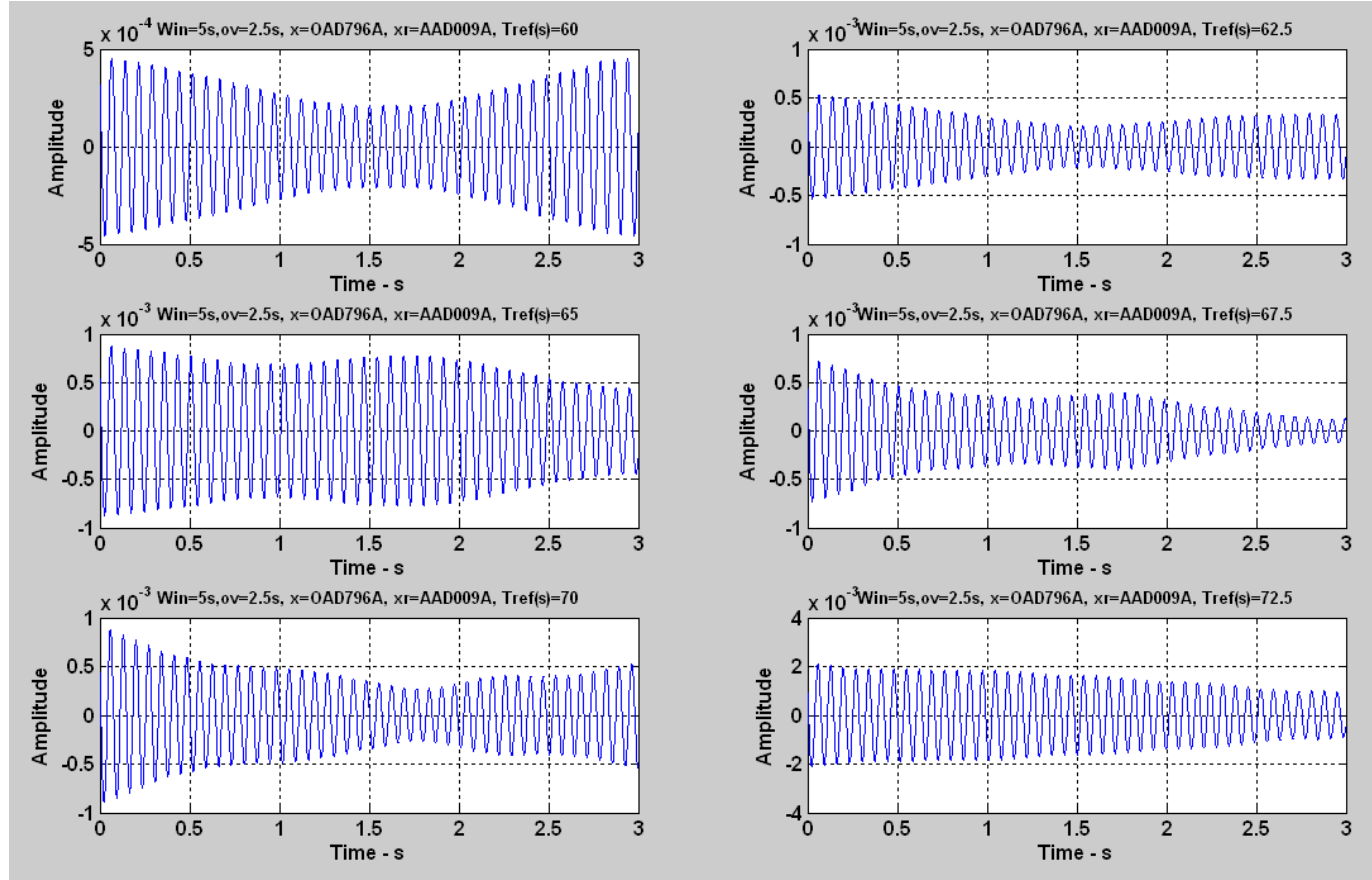

Figure 6. Ares I-X Cross Correlation Functions using Time-Zooming Technique

\section{In-Flight Modal Identification}

Modal parameters for three bending modes (bending modes 2-4) and first two axial modes were identified. Table 1 provides a summary of the modal parameters estimated from the Ares I-X flight data. The ERA was unable to identify the first bending mode $(1.5-2.0 \mathrm{~Hz})$ with a high level a confidence. Attempts to increase the analysis window size to characterize the first bending mode were unsuccessful. The identification of a low frequency mode from a system that is assumed "stationary" for a 5-second period is rather challenging. A longer time period is most likely needed to capture at least 6-8 cycles of the mode. It should be noted that since the force input is not white noise, modal damping estimates may be conservative (lower than actual) because the forced vibration can reduce the 
exponential decay rate of the cross-correlation. This is especially true if the forced excitation contains a high level of input in the narrow band frequency range of the structural mode.

Table 1. Summary of Modal Parameter Estimates from Ares I-X Flight Data

\begin{tabular}{|c|c|c|}
\hline Mode Description & Freq Range (Hz) & Damping Range ${ }^{*}(\%)$ \\
\hline $1^{\text {st }}$ Bending & $\mathrm{NA}^{\dagger}$ & $\mathrm{NA}^{\dagger}$ \\
\hline $2^{\text {nd }}$ Bending & $3.96-4.68$ & $\mathrm{NA}^{\ddagger}$ \\
\hline $3^{\text {rd }}$ Bending & $4.73-6.48$ & $0.2-0.8$ \\
\hline $4^{\text {th }}$ Bending & $7.36-12.0$ & $0.25-0.8$ \\
\hline $1^{\text {st }}$ Axial & $11.4-18.2$ & $0.2-1.0$ \\
\hline $2^{\text {nd }}$ Axial $^{\S}$ & $29.0-29.4$ & $0.05-0.3$ \\
\hline \multicolumn{3}{|c|}{$\begin{array}{l}\text { *: Damping values are believed to be conservative (lower than actual). } \\
{ }^{\dagger}: 1^{\text {st }} \text { bending mode could not be identified with high confidence. } \\
{ }^{\dagger}: \text { Damping value could not be estimated with high confidence. } \\
{ }^{\S}: 2^{\text {nd }} \text { Axial mode identified for the } 70-90 \text { second ascent period. }\end{array}$} \\
\hline
\end{tabular}

As previously stated, the modal parameter extraction was enhanced by separating data sets of axial and lateral measurements. The closed-loop frequencies and damping factors for the first axial mode were identified with an Extended Modal Assurance Criterion (EMAC) value of at least 90\%. The EMAC indicates the accuracy of identified modes with respect to measured responses. ${ }^{5}$ Figure 7 demonstrates the first axial mode was clearly identified throughout first stage burn with a frequency starting from $11.4 \mathrm{~Hz}$ at liftoff and ramping to $18.2 \mathrm{~Hz}$ near end of first stage burn. The estimated modal damping values range from $0.1 \%$ to $1.8 \%$, with a major between $0.2 \%$ and $1.0 \%$. Figure 7 also presents extracted modal parameters with EMAC values of at least $80 \%$ for the second axial mode, which was only identified during the 70-90 second ascent period. This is no surprise as the vehicle response spectrogram plots in Figures 4 and 5 show the presence of the mode during this time range. The second axial frequency is approximately $29.0-29.4 \mathrm{~Hz}$. The range of modal damping value is rather low (see Table 1 ) and is believed to be a very conservative estimate. Measured FS motor dome pressures showed a high level of frequency content near the $29 \mathrm{~Hz}$ second axial mode so the forced response contribution is not negligible in the cross correlation. Consequently, the cross correlation functions do not decay as fast, resulting in a lower, extracted damping value due to the forced vibration.

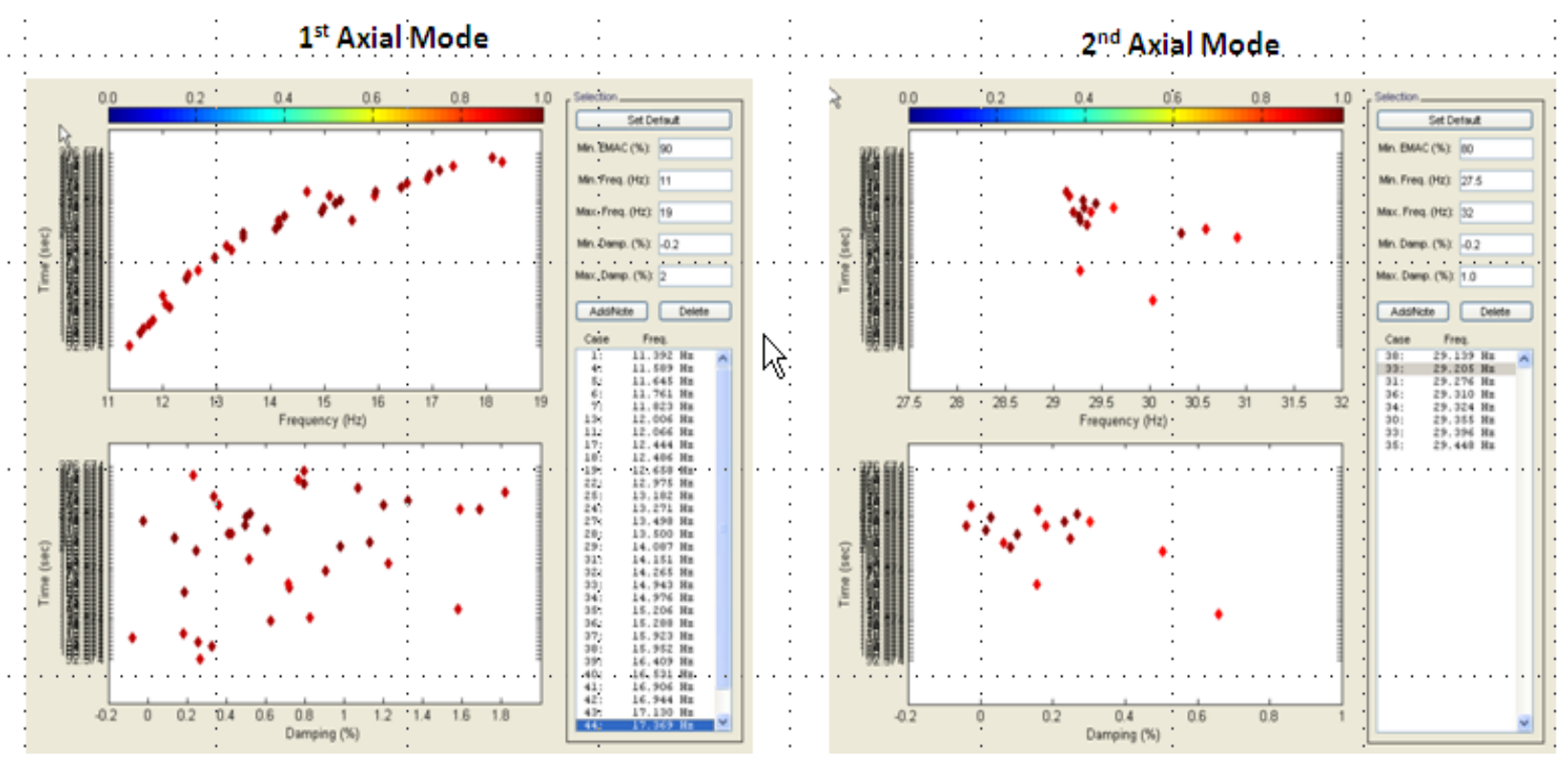

Figure 7. Ares I-X In-Flight Modal Parameter Estimates: 1 st and $2^{\text {nd }}$ Axial Modes

8

American Institute of Aeronautics and Astronautics 
The damping value for the Ares I-X second bending mode could not be extracted from the flight data with high confidence as shown in Figure 8. For several time windows, the ERA calculated a negative damping value. It is anticipated that a longer time window may increase the confidence in the modal extraction. The second bending mode shapes, however, looked consistent throughout ascent flight.

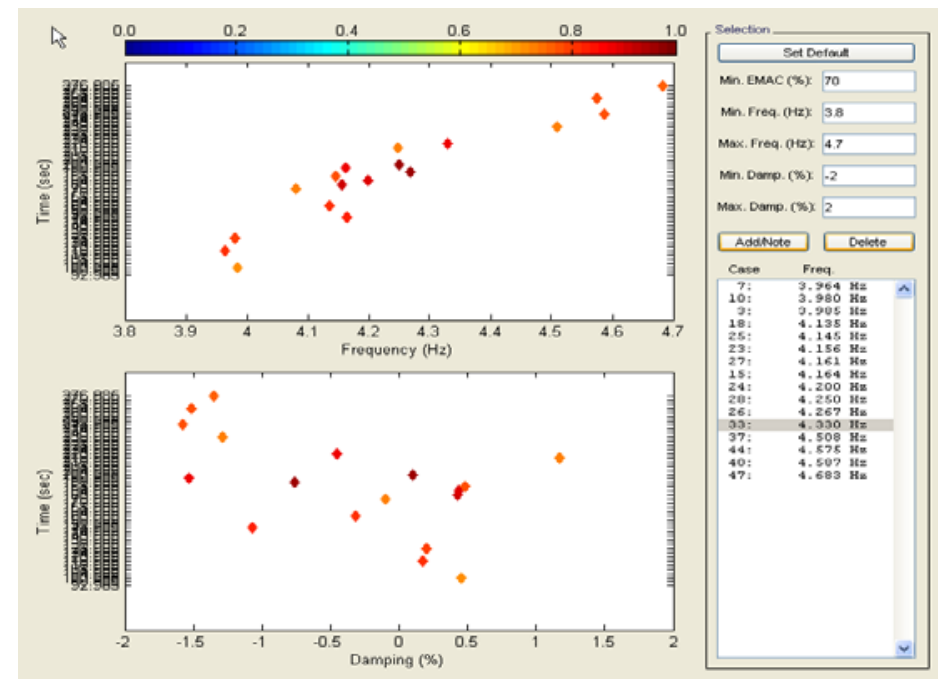

Figure 8. Ares I-X In-Flight Modal Parameter Estimates: $2^{\text {nd }}$ Bending Mode

Modal parameters for the third and fourth bending modes were extracted with higher confidence as shown in Figure 9. The third bending frequency shifted from $4.73 \mathrm{~Hz}$ near liftoff to $6.48 \mathrm{~Hz}$ near end of first stage burn. The modal damping range is approximately $0.2 \%-0.8 \%$. Similarly, the fourth bending frequency also shifted from 7.36 $\mathrm{Hz}-12.0 \mathrm{~Hz}$. Its modal damping range estimate is $0.25 \%-0.8 \%$.

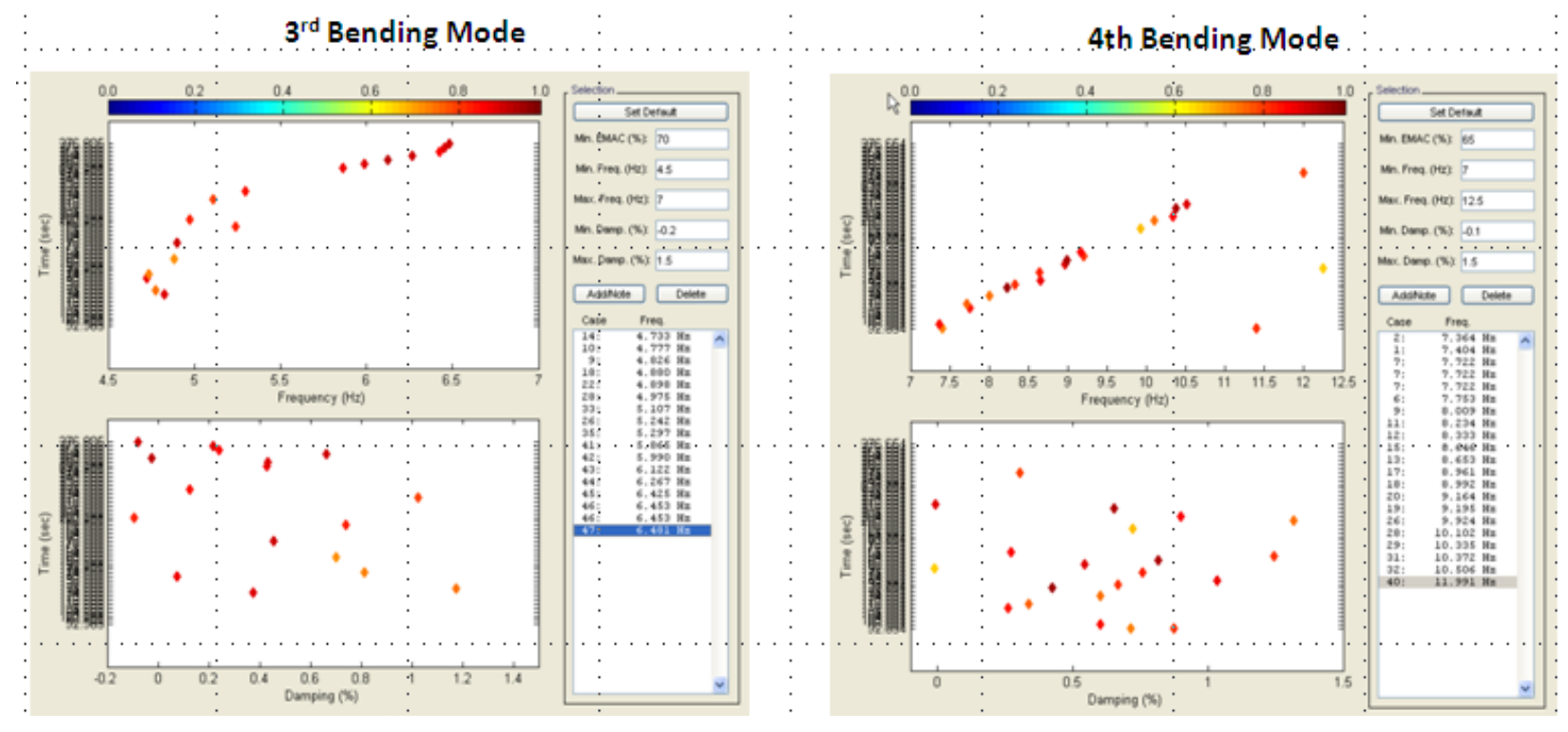

Figure 9. Ares I-X In-Flight Modal Parameter Estimates: $3^{\text {rd }}$ and 4th Bending Modes

In general, the range of modal damping may be conservative (lower that actual due to forced response). The modal damping of the first two axial and higher order $\left(3^{\text {rd }}\right.$ and $\left.4^{\text {th }}\right)$ bending modes was determined to be less than $1.0 \%$. Ares I-X modal test results also showed damping values less than $1 \%$ for bending modes. ${ }^{14}$ Although the 
Ares I-X modal test were performed on the Mobile Launch Platform (MLP) in a fixed-free boundary condition, there is a strong similarity between the free-free bending modes in-flight and the second through fourth bending modes on the MLP. ${ }^{3}$

Ares I-X in-flight mode shapes were also extracted from the ERA. Since the modal identification was performed on a series of linearized models using a sliding-time window, mode shapes were obtained at various, discrete times during the ascent period. Some modes were more easily identified and tracked throughout the first 120 seconds of ascent and thus have a higher number of instances. The modal assurance criterion (MAC) was employed to track modes during ascent, where the MAC indicates the degree of agreement between two sets of mode shapes. ${ }^{15}$ An AutoMAC was calculated for each of the in-flight (test) modes. Figures 10 and 11 display the AutoMAC for the inflight axial and bending modes, respectively, in which the following conclusions can be drawn. The first axial mode shape is very consistent throughout from liftoff to the end of first stage burn as shown by the "red" bandwidth (MAC $>0.9$ ) in its AutoMAC plot. The second axial mode, which was only extracted during the 70-90 second ascent period, also maintained is shape fairly well. The shapes of the extracted in-flight second, third and fourth bending modes do not show the same consistency as the first two axial modes.

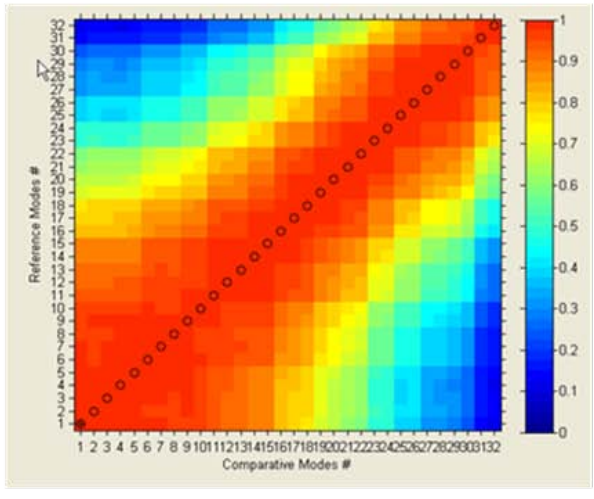

Auto MAC - 1st $^{\text {Axxial In-Flight Mode }}$

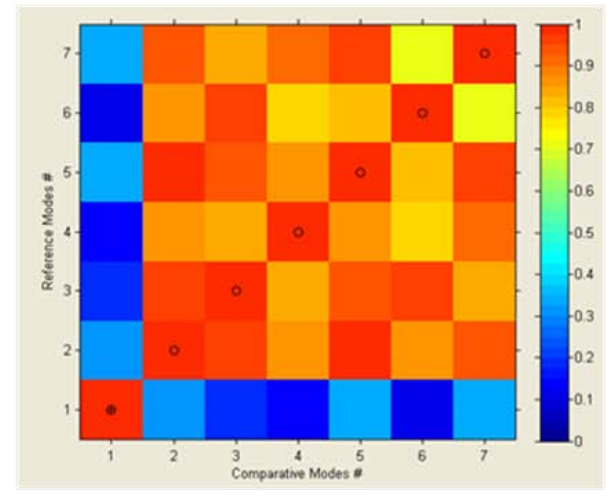

Auto MAC $-2^{\text {nd }}$ Axial In-Flight Mode

Figure 10. AutoMAC of Ares I-X In-Flight Mode Shapes - Axial

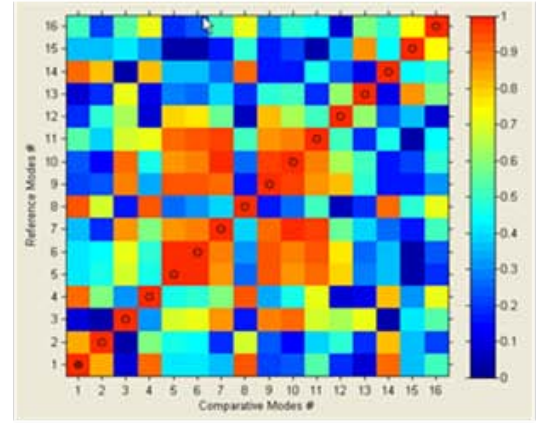

Auto MAC - $2^{\text {nd }}$ Bending In-Flight Mode

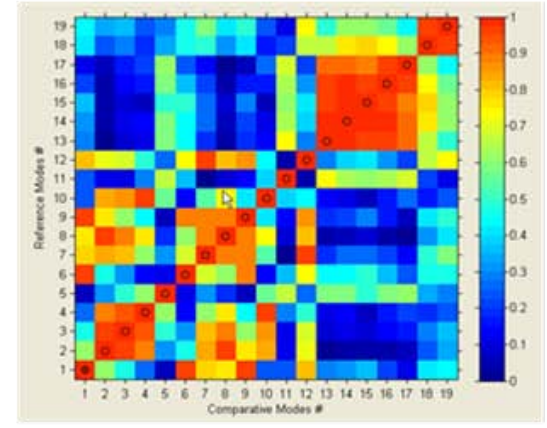

Auto MAC $-3^{\text {rd }}$ Ben ding In-Flight Mode

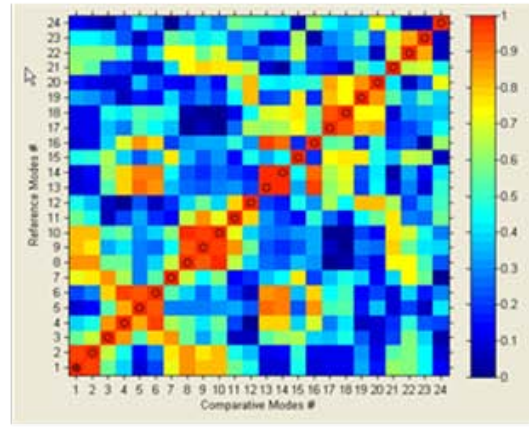

Auto MAC $-4^{\text {th }}$ Bending In-Flight Mode

Figure 11. AutoMAC of Ares I-X In-Flight Mode Shapes - Bending

An important fact is that the in-flight (damped) modes are very complex. To investigate the shape change of each mode during ascent, a real-mode estimation was performed to convert complex mode shapes into real (undamped) mode shapes. Two approximation techniques were employed for the complex-to-real conversion, a "simple" modulus/phase method and a mode rotation method. The simple method converts mode shapes from complex to real by taking the modulus and by assigning a phase to each of either $0^{\circ}$ or $180^{\circ}$. A phase angle between $\pm 90^{\circ}$ is set to $0^{\circ}$ and between $90^{\circ}$ and $270^{\circ}$ is set to $180^{\circ}$. The mode rotation method rotates the (complex) mode shape to show maximum real values. The results indicated the mode rotation method was more robust. 
Static mode shape plots were also developed to track shape change. Figure 12 illustrates the first axial mode shape is very consistent for $\mathrm{T}<80$ seconds, makes a shape transition around $\mathrm{T}=80$ (T80) seconds, and then is very consistent for $\mathrm{T}>80$ seconds. At the earlier part of ascent $(\mathrm{T}<80$ seconds), the shape resembles the shape of a second axial mode. During the later part of ascent, the mode shape looks like a fundamental first axial mode. It was originally thought there was a polarity error in DFI channels located at X-station $<2000$ inches for the early ascent modes. However, $\mathrm{X}$-channels sensor polarities were confirmed by the time history plots of the axial acceleration channels.

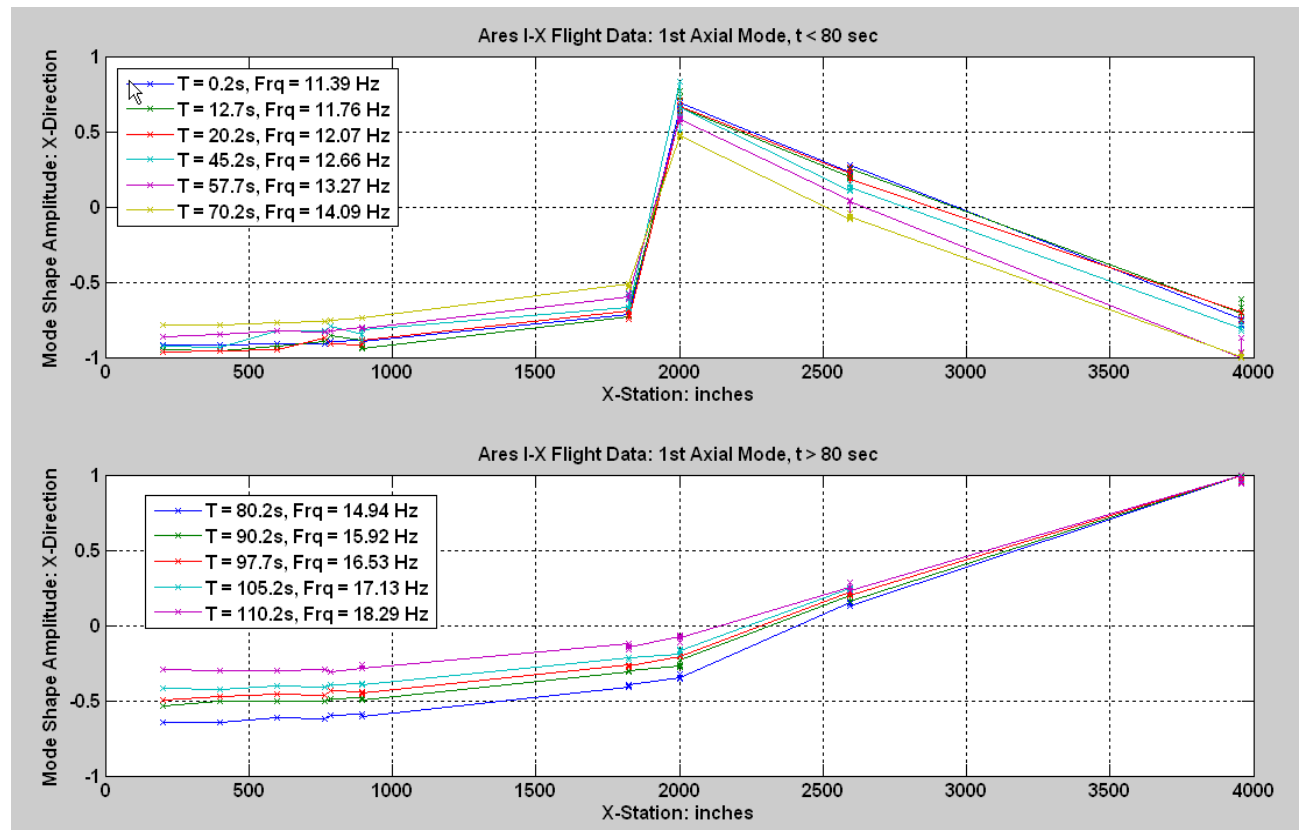

Figure 12. Shape Change of Ares I-X $1^{\text {st }}$ Axial In-Flight Mode

A brief investigation on any peculiar activity around T80 was examined. It was learned that a pitch/yaw Programmed Test Input (PTI) had occurred during that time. ${ }^{16}$ In addition, test data showed the second longitudinal (2-L) acoustic mode shifts to line-up with the second axial vehicle mode. It is not suspected that these activities attributed to the mode shape shift found in the extracted mode.

Mode shape animations also showed the same shape and shape transition characteristic as illustrated in the static plots but were not identified in the AutoMAC (see Figure 9). This finding reveals a limitation in the MAC when the modes are very complex. The MAC calculation ${ }^{17}$ of Eq. (8) shows that the magnitude of complex modes is used which results in a real value for the MAC.

$$
M A C_{A, B}=\frac{\left|\sum_{j=1}^{n}\left(\phi_{A}\right)_{j}\left(\phi_{B}\right)^{*}{ }_{j}\right|^{2}}{\left(\sum_{j=1}^{n}\left(\phi_{A}\right)_{j}\left(\phi_{A}\right)^{*}{ }_{j}\right)\left(\sum_{j=1}^{n}\left(\phi_{B}\right)_{j}\left(\phi_{B}\right)^{*}{ }_{j}\right)}
$$

It appears that the modal vector estimates may be consistent but does not necessary imply that they are correct and therefore, cannot be delineated by the MAC. ${ }^{17}$ Regardless of the dramatic shape change at T80, a nodal point continues to shift forward throughout the ascent phase, which is expected due to the burning of the FS propellant. Figure 13 shows the AutoMAC for the approximated, real mode shapes for the first axial mode during ascent. The results agree with the static mode shape plots in Figure 12. 


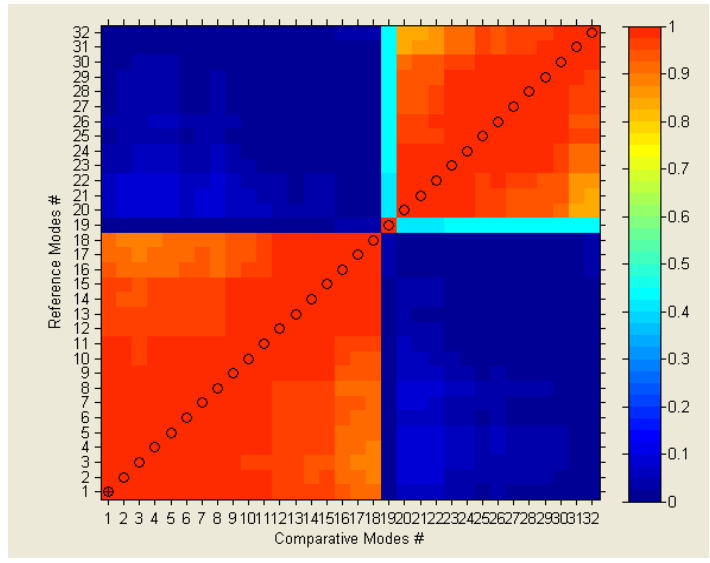

Figure 13. Shape Change of Ares I-X $1^{\text {st }}$ Axial In-Flight Mode

Static (real) mode shapes and their corresponding AutoMAC are presented in Figure 14 for the in-flight second axial mode. The two shape outliers, which are clearly indicated in the figure, appear to be corrected with a phase polarity change. AutoMAC comparisons were also produced for both complex and approximated (real) modes for the second, third and fourth bending modes. The shape tracking of bending modes was not a major focus of this study a comparison of in-flight versus FEM bending modes will be presented in a later section. It appears that error is introduced in the real normalization of complex modes. Further work is needed in this area.
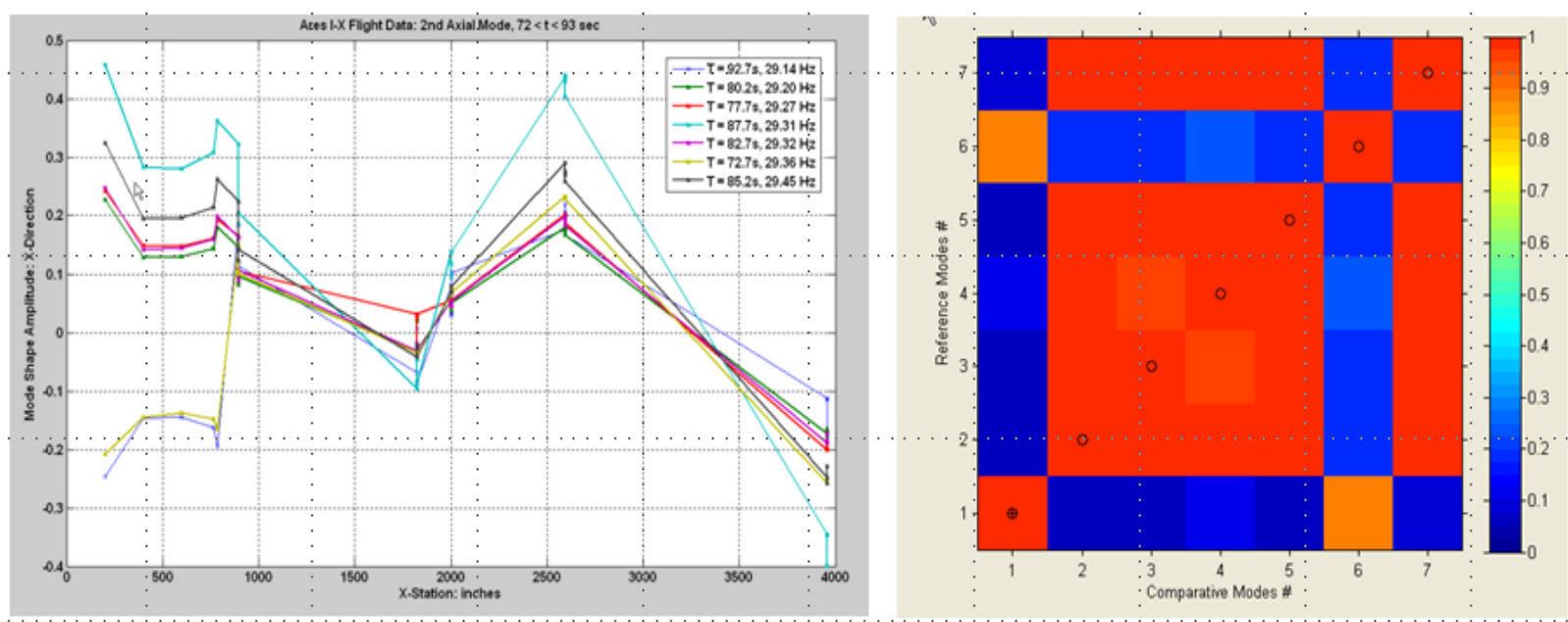

Figure 14. Static Mode Shape and AutoMAC of (Approximated) $2^{\text {nd }}$ Axial Mode

\section{Finite Element Models}

NASA-LARC provided IVM13b_1315 finite element models (FEMs) at 10 second intervals from $t=10$ seconds (T10) through $\mathrm{t}=120$ seconds (T120). Boeing initially developed Craig-Bampton (C-B) models for a partial set of these configurations to assess different ascent events including, max buffet (T40), max aerodynamic pressure (T60) and maximum thrust oscillation (T80). A few additional configurations were developed to further track modes during flight. The reduced C-B models contained 636 physical degrees-of-freedom (dofs), otherwise known as the NASTRAN b-set. Grids points retained for the reduced model included 54 centerline grids, 24 grids at both FS/US and US/SM interfaces ( $24 \times 2=48$ grids) plus aft-skirt grids. Mode shapes were extracted from the 315 translational dofs from the physical set, 162 of these are vehicle centerline dofs from 54 centerline grids. 


\section{A. Mode Tracking}

Table 1contains a tracking of the first five bending and first two axial modes at various ascent time increments. Mode shape animations and static plots were used to identify and track modes. The MAC was also employed to track modes during ascent. The MAC values are based on 315 dofs. For the mode shape tracking, the $\mathrm{T}=50$ second model (T50) was used as a reference model.

Table 1. Ares I-X FEM Modal Frequencies vs. Time

\begin{tabular}{|c|c|c|c|c|c|c|c|}
\hline & \multicolumn{7}{|c|}{$\begin{array}{c}\text { Ares I-X Models } \\
\text { Frequency (Hz) [MAC }]\end{array}$} \\
\hline $\begin{array}{c}\text { Mode } \\
\text { Description }\end{array}$ & $\begin{array}{c}\text { T50 } \\
\text { (Ref) }\end{array}$ & T40 & T60 & T80 & T90 & T100 & T110 \\
\hline $1^{\text {st }}$ Bending & 1.60 & $1.54[1.0]$ & $1.66[1.0]$ & $1.77[1.0]$ & $1.84[1.0]$ & $1.87[1.0]$ & $1.92[1.0]$ \\
\hline $2^{\text {nd }}$ Bending & 3.99 & $3.91[1.0]$ & $4.08[1.0]$ & $4.30[0.97]$ & $4.44[0.92]$ & $4.57[0.84]$ & $4.70[0.50]$ \\
\hline $3^{\text {rd }}$ Bending & 5.01 & $4.99[1.0]$ & $5.03[1.0]$ & $5.12[0.98]$ & $5.21[0.96]$ & $5.39[0.92]$ & $5.99[0.70]$ \\
\hline $4^{\text {th }}$ Bending & 8.70 & $8.31[0.97]$ & $9.03[1.0]$ & $9.74[0.98]$ & $10.21[0.95]$ & $10.65[0.90]$ & $11.43[0.53]$ \\
\hline $1^{\text {st }}$ Axial & 12.18 & $11.85[1.0]$ & $12.62[0.99]$ & $13.69[0.74]$ & $14.36[0.45]$ & $15.80[0.55]$ & $17.42[0.51]$ \\
\hline $5^{\text {th }}$ Bending & 13.33 & $13.02[1.0]$ & $13.59[1.0]$ & $14.26[0.88]$ & $15.32[0.96]$ & $16.72[0.69]$ & $18.76[0.52]$ \\
\hline $2^{\text {nd }}$ Axial & 23.08 & $24.00[0.97]$ & $24.38[0.99]$ & $23.97[0.91]$ & NA & NA & NA \\
\hline${ }^{*}$ MAC based on 315 dofs.
\end{tabular}

Table 1 shows that the second axial mode was nearly impossible to track after $\mathrm{T}=80$ seconds (T80) in the Ares I$\mathrm{X}$ C-B FEMs. It was extremely difficult to find the second axial mode from mode shapes animations, which are limited since they based on 315 dofs. This suggests that a greater number of model dofs must be retained to identify the second axial mode. The MAC value for the first axial mode also began to drop beginning T80.

\section{B. Analytical Mode Shapes}

In order to make a direct comparison between analytical and test mode shapes, twenty-seven (27) grid points were added in the analytical model at the locations of the DFI accelerometers. In several instances, one grid represents three accelerometers (triaxial). These grids were rigidly attached (via RBE2 elements) to the closest point in the FEM. Analytical frequencies and mode shapes were extracted from the full BULKDATA model with DFI grids included. The modes shapes were subsequently partitioned to 56 DFI dofs, which included the original 58 channels minus channel IDs: AAD013A and AAD016A; both were initially found to be bad channels. Three full BULKDATA models (T60, T80 and T100) with DFI sensor locations were created for this post-flight reconstruction effort.

Static mode shapes were created for both vehicle centerline dofs and DFI sensor dofs. Figures 15 through 17 show the differences in mode shapes between these two dof sets of the Ares I-X T80 FEM. The plots show that DFI spatial distribution on the first stage was too sparse to adequately describe mode shapes above the fundamental axial and bending modes and the issue became more apparent in higher bending modes as shown in Figure 17. It is important to note that the Ares I-X flight did not have an objective to validate higher order modes but additional FS DFI accelerometer measurements would have aided the mode shape characterization. For future flights, a better spatial distribution of flight sensors is needed to characterize higher order bending modes. It is recommended that at least two sensors are located between modal max/min points to discriminate modes. 


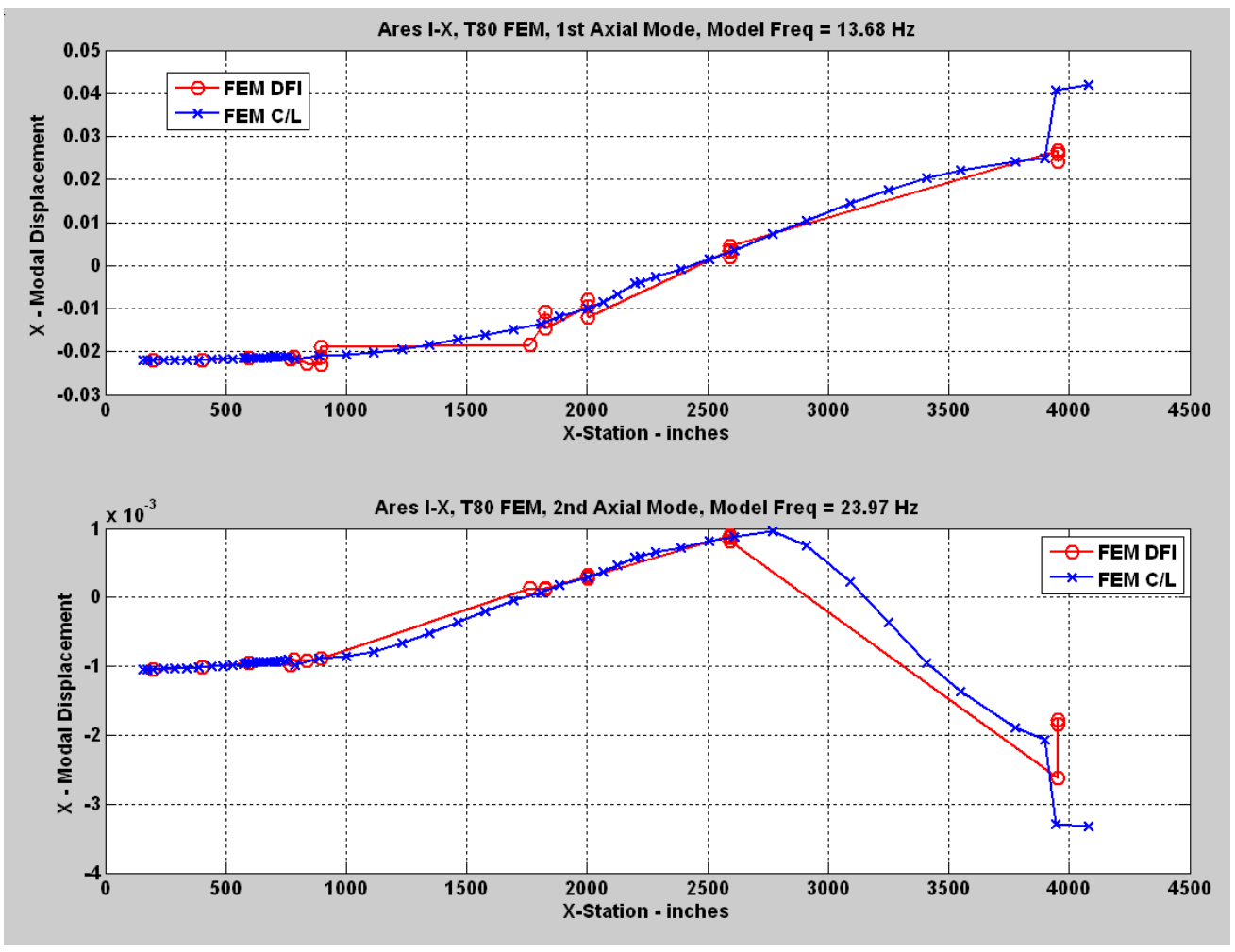

Figure 15. T80 FEM $1^{\text {st }} \& 2^{\text {nd }}$ Axial Modes, DFI vs. Vehicle Centerline DOFs
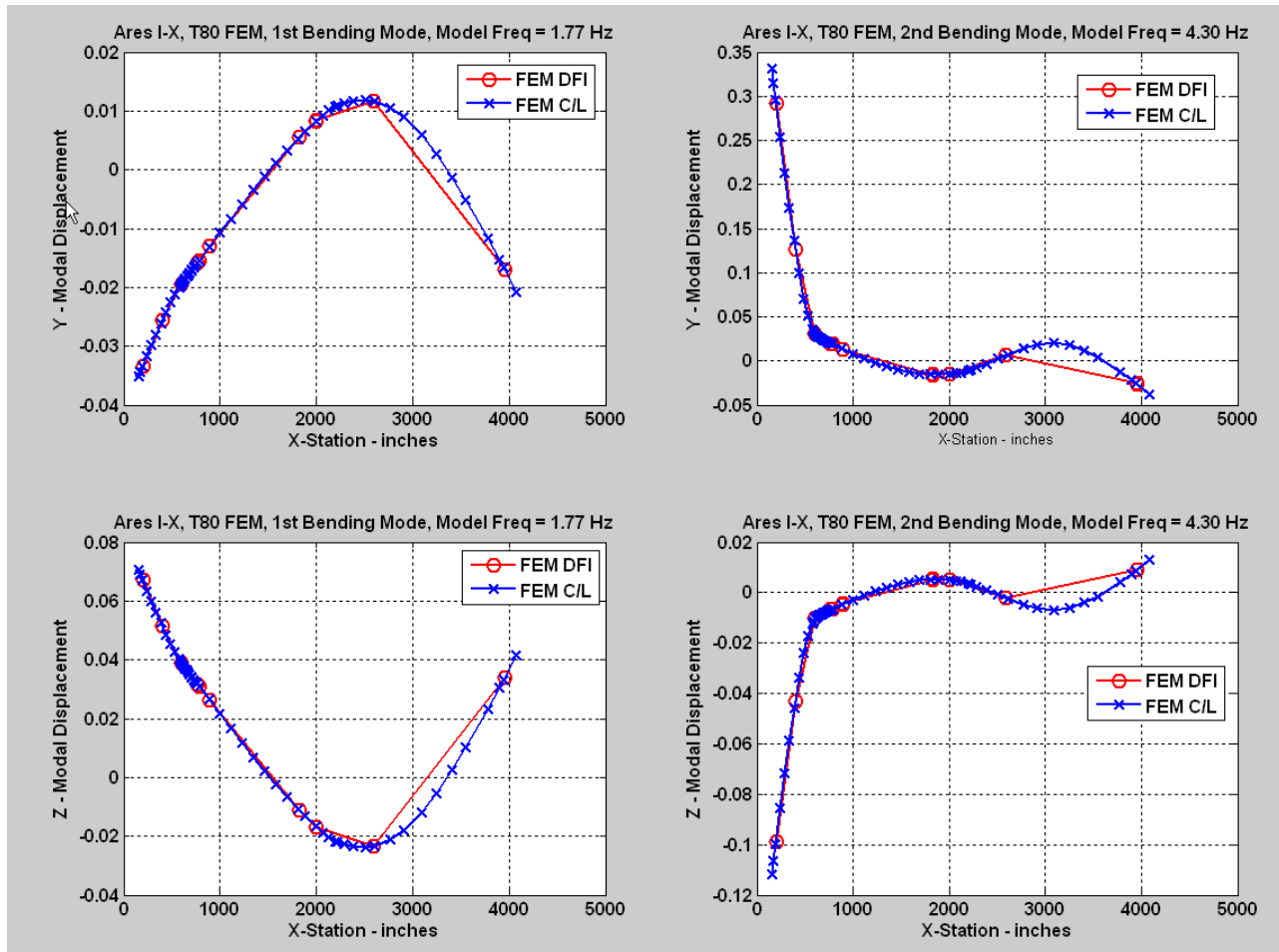

Figure 16. T80 FEM $1^{\text {st }} \& 2^{\text {nd }}$ Bending Modes, DFI vs. Vehicle Centerline DOFs

American Institute of Aeronautics and Astronautics 


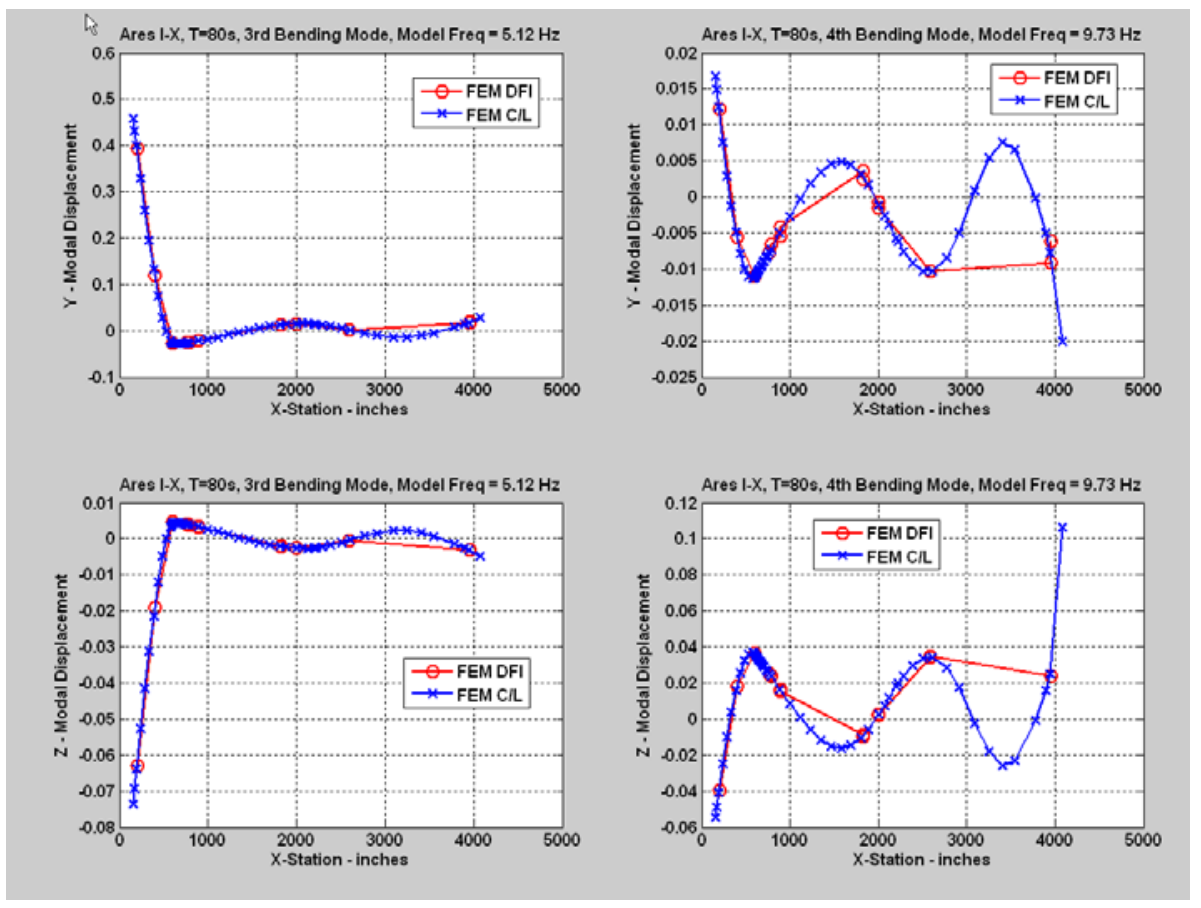

Figure 17. T80 FEM $3^{\text {rd }} \& 4^{\text {th }}$ Bending Modes, DFI vs. Vehicle Centerline DOFs

\section{Test/Analytical Mode Comparison}

\section{A. Frequency Comparison}

A comparison of Ares I-X test to analytical modes is shown in Table 2 for three (T60, T80 and T100) different ascent times. In general, the FEMs are softer than the vehicle since in-flight frequencies are higher than analytical frequencies. Furthermore, frequency errors for the first axial and higher $\left(3^{\text {rd }}\right.$ and $\left.4^{\text {th }}\right)$ bending modes increase above $5 \%$ in the latter (T80 \& T100) models. More significantly, the T80 model underpredicted the second axial mode frequency by approximately $18 \%$. As previously noted, the second axial mode was only identified during the T70T90 period. The frequency errors do not meet the frequency correlation guidelines of $\pm 5 \%$ and $\pm 10 \%$ frequency differences on significant and higher order modes, respectively, per Constellation Structural Loads Control Plan. ${ }^{18}$ This suggests that model refinement is needed. However, no efforts have been made to refine the model for postflight loads analysis. It appears the modeling to account of fuel mass loss needs improvement because model frequency error tends to increase during ascent time.

Table 2. Comparison of Ares I-X Test vs. Analytical Modes

\begin{tabular}{|c|c|c|c|c|c|c|c|c|c|c|c|c|}
\hline & \multicolumn{4}{|c|}{ T60 } & \multicolumn{4}{|c|}{ T80 } & \multicolumn{4}{|c|}{ T100 } \\
\hline $\begin{array}{l}\text { Mode } \\
\text { Desc. }\end{array}$ & $\begin{array}{l}\text { Test } \\
\text { Frq. } \\
(\mathrm{Hz})\end{array}$ & $\begin{array}{l}\text { FEM } \\
\text { Frq. } \\
(\mathrm{Hz})\end{array}$ & $\begin{array}{l}\text { Frq. } \\
\text { Diff. } \\
(\%)\end{array}$ & $\mathrm{MAC}^{*}$ & $\begin{array}{l}\text { Test } \\
\text { Frq. } \\
(\mathrm{Hz})\end{array}$ & $\begin{array}{l}\text { FEM } \\
\text { Frq. } \\
(\mathrm{Hz})\end{array}$ & $\begin{array}{l}\text { Frq. } \\
\text { Diff. } \\
\text { (\%) }\end{array}$ & $\mathrm{MAC}^{*}$ & $\begin{array}{l}\text { Test } \\
\text { Frq. } \\
(\mathrm{Hz})\end{array}$ & $\begin{array}{l}\text { FEM } \\
\text { Frq. } \\
(\mathrm{Hz})\end{array}$ & $\begin{array}{l}\text { Frq. } \\
\text { Diff. } \\
\text { (\%) }\end{array}$ & $\mathrm{MAC}^{*}$ \\
\hline $\begin{array}{c}1^{\text {st }} \\
\text { Axial }\end{array}$ & 13.18 & 12.62 & 4.2 & $0.14 X$ & 14.94 & 13.68 & 8.4 & $0.98 \times$ & 16.91 & 15.78 & 6.7 & $0.90 \times$ \\
\hline $\begin{array}{c}2^{\text {nd }} \\
\text { Axial }\end{array}$ & NA & 24.38 & NA & NA & 29.20 & 23.97 & 17.9 & $0.52 x$ & NA & NA & NA & NA \\
\hline $\begin{array}{l}2^{\text {nd }} \\
\text { Bend }\end{array}$ & 4.14 & 4.08 & 1.4 & $\begin{array}{l}0.98 Y \\
0.95 Z\end{array}$ & 4.33 & 4.30 & 0.7 & $\begin{array}{l}0.96 Y \\
0.97 \mathrm{Z}\end{array}$ & 4.59 & 4.57 & 0.4 & $\begin{array}{l}0.97 Y \\
0.98 Z\end{array}$ \\
\hline $\begin{array}{c}3^{\text {rd }} \\
\text { Bend }\end{array}$ & 5.24 & 5.03 & 4.0 & $\begin{array}{l}0.97 Y \\
0.92 Z\end{array}$ & 5.11 & 5.12 & -0.2 & $\begin{array}{l}0.96 \mathrm{Y} \\
0.97 \mathrm{Z}\end{array}$ & 5.86 & 5.40 & 7.8 & $\begin{array}{l}0.75 Y \\
0.83 Z\end{array}$ \\
\hline $\begin{array}{c}4^{\text {th }} \\
\text { Bend }\end{array}$ & 9.53 & 9.03 & 5.2 & $\begin{array}{l}0.02 Y \\
0.15 \mathrm{Z}\end{array}$ & 10.51 & 9.73 & 7.4 & $\begin{array}{l}0.02 Y \\
0.05 Z\end{array}$ & 11.99 & 10.67 & 11.0 & $\begin{array}{l}0.08 Y \\
0.12 Z\end{array}$ \\
\hline
\end{tabular}




\section{B. Mode Shape Comparison}

Analytical mode shapes were also compared using both MAC and static mode shape plots. In order to ensure comparability between FEM and measured in-flight modes, real estimates of (complex) test modes were employed. Table 3 includes MAC values with the mode frequency differences for three (T60, T80 and T100) ascent configurations. Since the mode shapes were extracted from ERA based on either axial DFI measurements for axial modes or transverse DFI measurements for bending modes, the MAC values are based solely on those dofs. These include 23 dofs for MAC-X, 15 dofs for MAC-Y and 14 dofs for MAC-Z. In general, there is good MAC agreement for the second and third bending modes. The poor MAC value in the first axial mode at T60 is believed to be due to the real mode approximation since the shape was very consistent (see Figure 11 ) for $T<80$ seconds. The low MAC value for the fourth bending mode may be attributed to either poor modal extraction and/or errors in the real mode approximation. The low MAC value for the second axial mode may be attributed to the poor test/analysis correlation of this mode, since its analytical frequency differs about $18 \%$ from the measured value.

Figure 18 shows the test/analytical mode shape comparison of the second axial mode at T80. This mode was only observed during the T70-T90 ascent period. It appears that the FEM underpredicts the modal deflection at the forward end $(\mathrm{X}<200$ in.) of the vehicle.

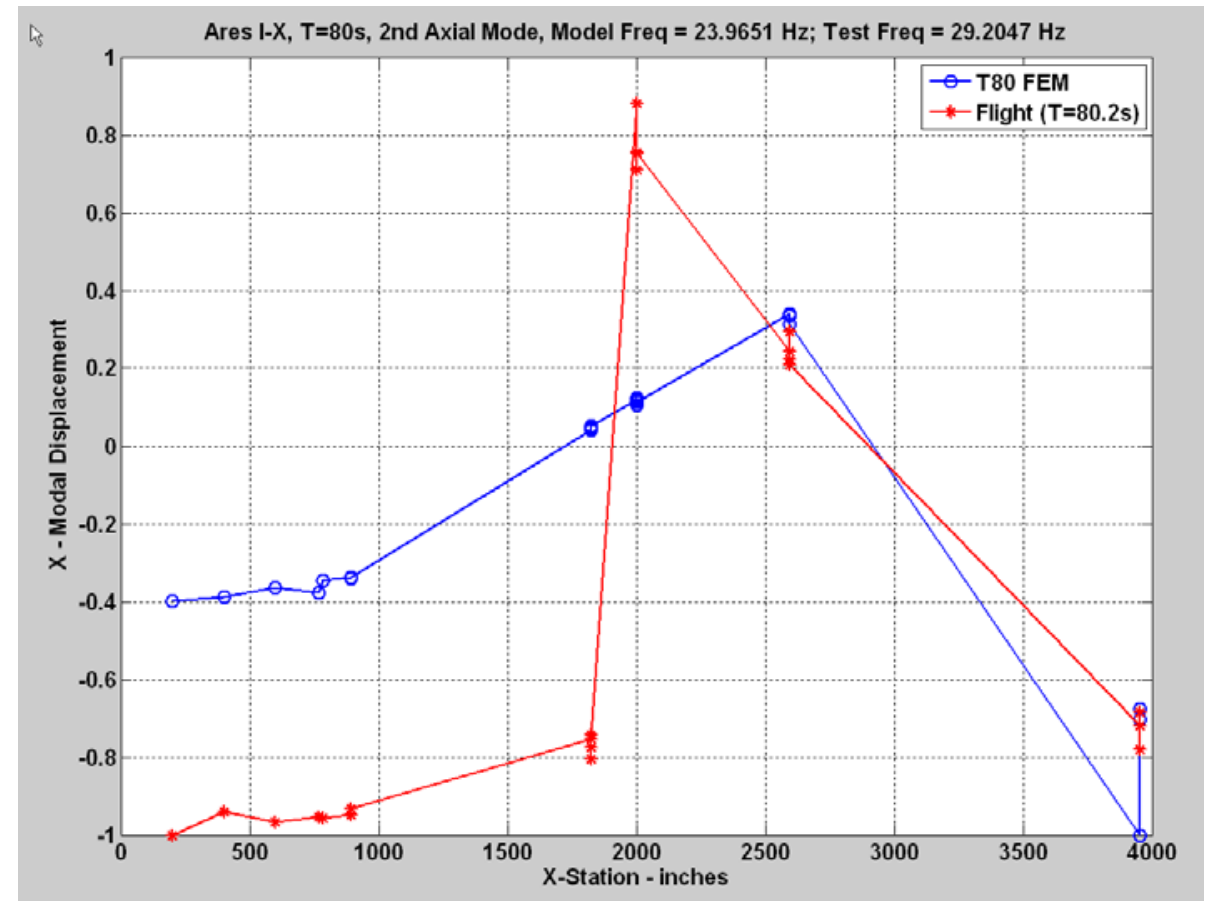

Figure 18. Ares I-X Test vs. Analytical $2^{\text {nd }}$ Axial Mode Shape Comparison

Figures 19 through 21 present a comparison of test and analytical mode shapes for the second, third and fourth bending modes, respectively. In general, the shape comparisons are good. There appears to be some phase (sign) differences in the modal deflections that are believed to be attributed to the real mode estimation process of test modes. Phase issues have consistently manifested among the extracted modes near the middle of the vehicle (vehicle station $X=2000$ in.). Further work is needed to produce real normal modes from measured complex responses. 

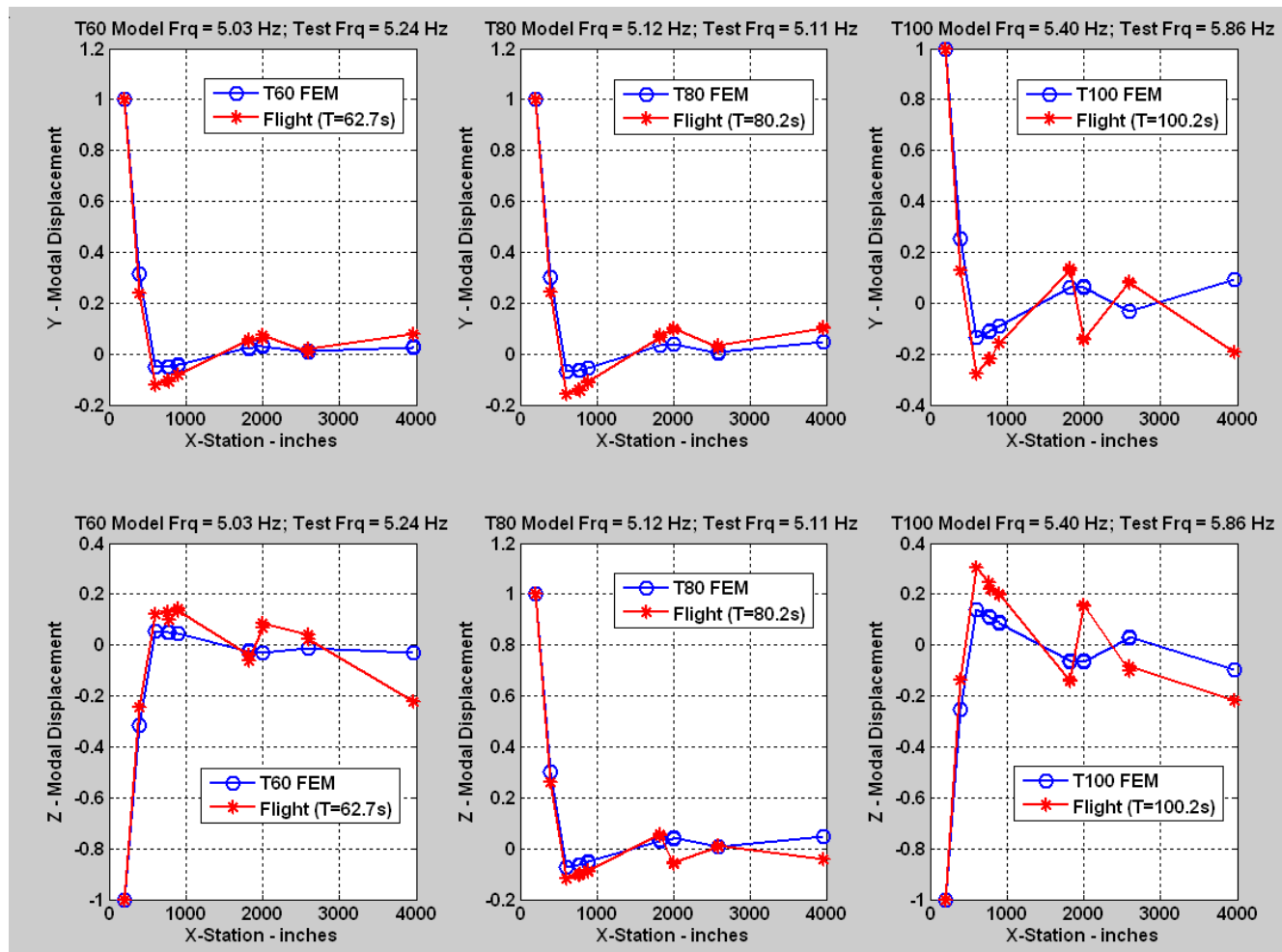

Figure 19. Ares I-X Test vs. Analytical $2^{\text {nd }}$ Bending Mode Shape Comparison
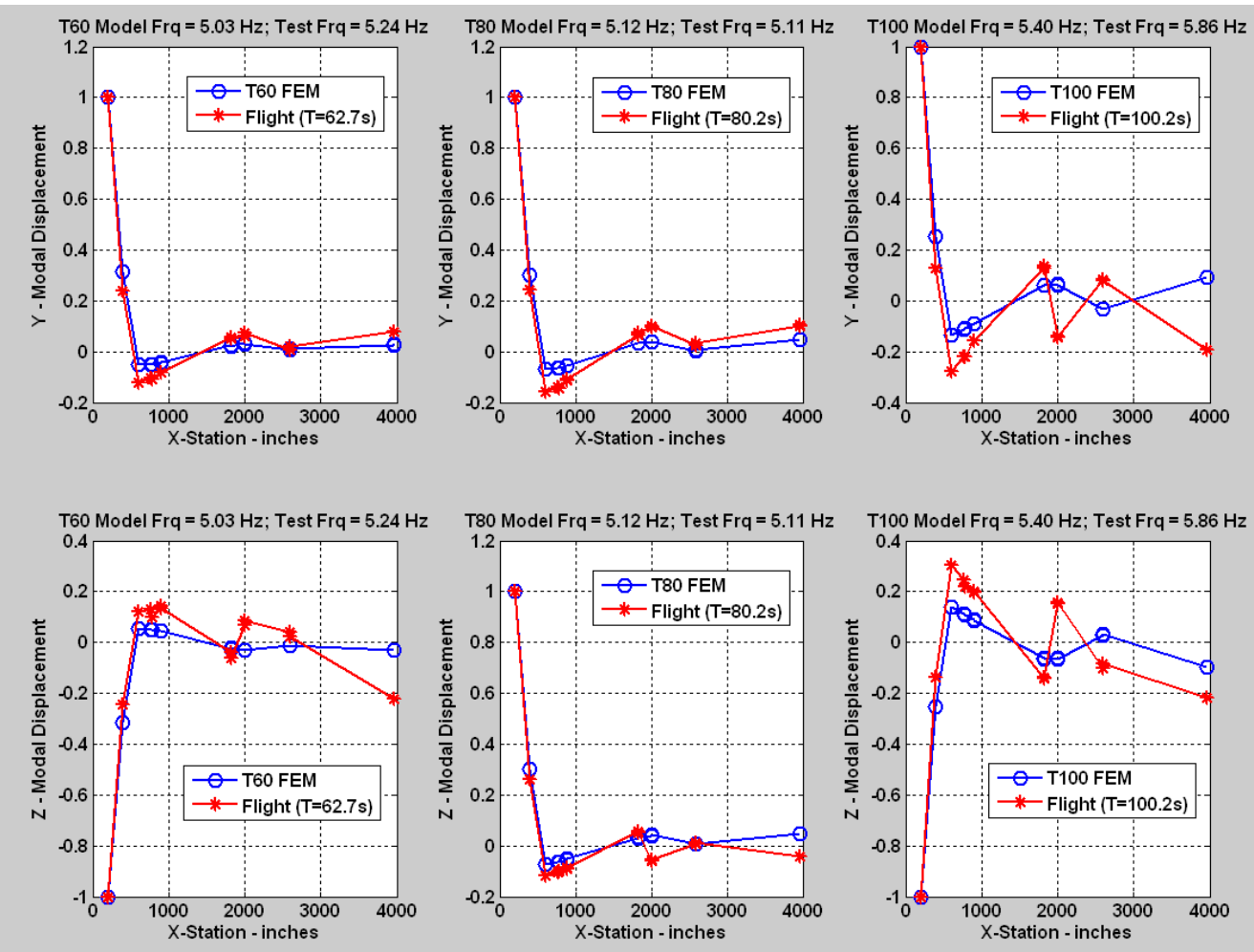

Figure 20. Ares I-X Test vs. Analytical $3^{\text {rd }}$ Bending Mode Shape Comparison

American Institute of Aeronautics and Astronautics 


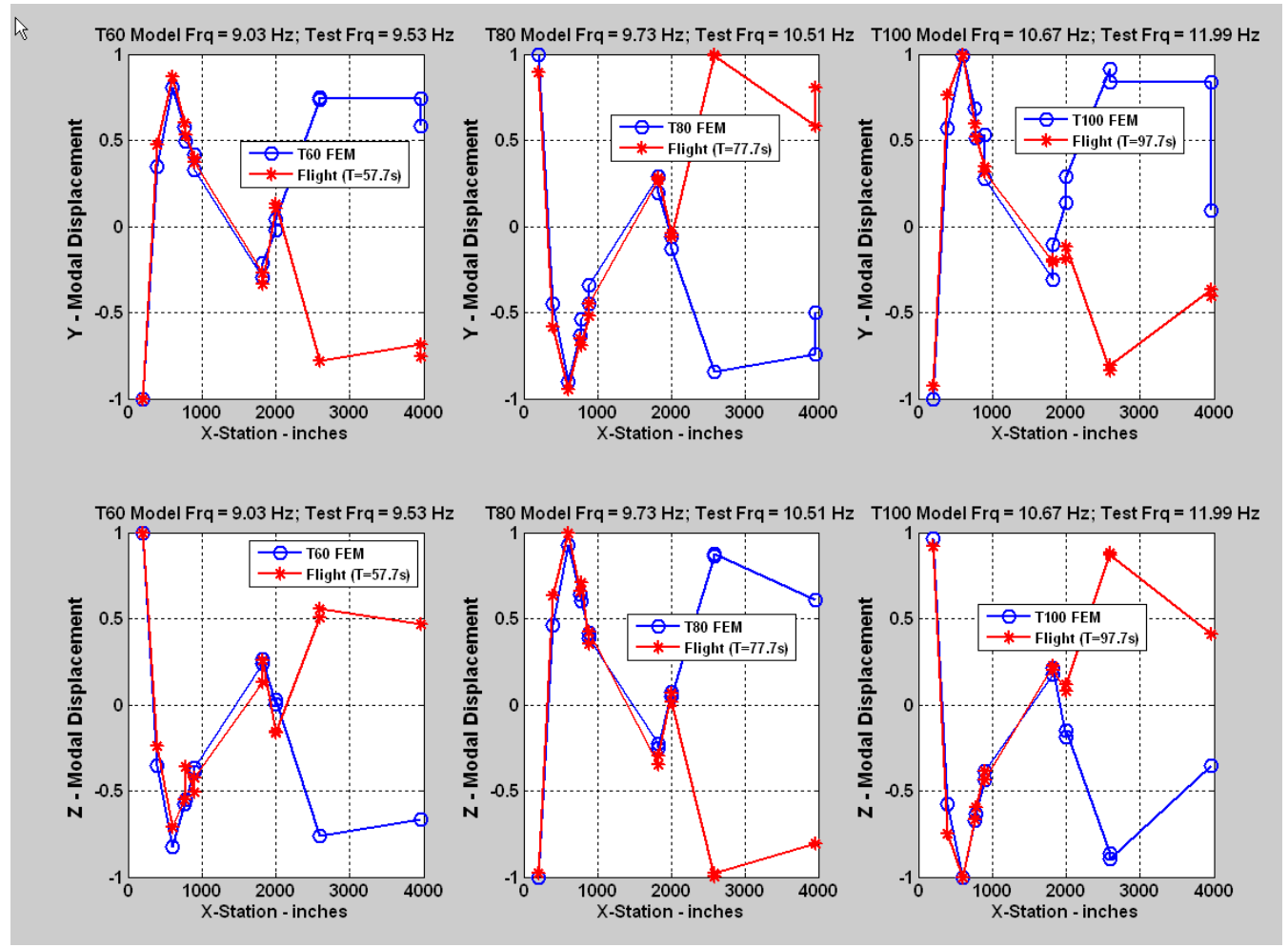

Figure 21. Ares I-X Test vs. Analytical $4^{\text {th }}$ Bending Mode Shape Comparison

\section{Conclusions}

A free-decay time-domain model identification technique has been developed to address major issues and solutions to extract modal parameters from in-flight data of a non-stationary dynamic system. A data processing strategy was presented to generate equivalent free-decay responses from structural response data subject to unmeasured random input. The results demonstrate the technique can be applied to in-flight data and successfully extract modal parameters of a launch vehicle. Further work is needed to overcome the difficulties associated with approximating real normal modes from measured complex modes, which will help in the analysis/test mode shape comparison.

\section{References}

${ }^{1}$ NASA Fact Sheet, Constellation Program: Ares I-X Flight Test Vehicle, FS-2009-03-007-JSC, 2009, http://www.nasa.gov/pdf/354470main_aresIX_fs_may09.pdf

${ }^{2}$ Ares I-X Post Flight Data Analysis Plan, NASA Report No. AI1-SYS-DAP, Version1.0, May 5, 2009.

${ }^{3}$ Buehrle, R. D., et al., “Ares I-X Launch Vehicle Modal Test Overview," Proc. 48 ${ }^{\text {th }}$ International Modal Analysis Conference, Paper No. 234, Jacksonville, FL, Feb. 2010.

${ }^{4}$ Horta, L. G., et al., "Finite Element Model Calibration Approach for Ares I-X," Proc. 48 ${ }^{\text {th }}$ International Modal Analysis Conference, Jacksonville, FL, Feb. 2010, 18 pp.

${ }^{5}$ Juang, J. N. and Pappa, R. S., "An Eigensystem Realization Algorithm for Modal Parameter Identification and Model Reduction,” J. Guidance, Vol. 8, No. 5, Oct. 1985, pp. 620-627.

${ }^{6}$ Trombetta. D. R., Ares I-X DFI/OFI Measurement List, AI1-SYS-DFI, Rev. 3.10, August 10, 2009.

${ }^{7}$ Templeton, J. D., and Buehrle, R. D., “Ares I-X Technical Analysis Report: Ares I-X Launch Vehicle Assessment of InFlight Modes,” NASA Report No. AIX-TAR-STR0007, May 3, 2010.

${ }^{8}$ Allemang. R. J., “Multiple Input Experimental Modal Analysis - A Survey,” International Journal of Analytical and Experimental Modal Analysis, Vol. 1, No. 1, 1986, pp. 37-44.

${ }^{9}$ Carbon. G. D., “Ground Vibration Testing at Boeing,” Sound and Vibration, Vol. 18, No. 6, 1984, pp. 16-20. 
${ }^{10}$ Kim, H. M., VanHorn, D.A., and Doiron, H. H., "Free-Decay Time-Domain Modal Identification for Large Space Structures,” Journal of Guidance, Control and Dynamics, Vol. 17, No. 3, 1994, pp. 513-519.

${ }^{11}$ Bendat, J. S., and Piersol, A. G., Random Data: Analysis and Measurement Procedures $-2^{\text {nd }}$ Edition, Wiley, New York, 1971, pp. 28-31.

${ }^{12}$ James. G. H., Carne, T. G., and Lauffer, J. P., "The Natural excitation Technique (NeXT) for Modal Parameter Extraction From Operating Wind Turbines,” Sandia Report No. SAND92-1666, Feb. 1993, pp. 8-12.

${ }^{13}$ James. G. H., Cao, T. T., Fogt, V. A., Wilson, R. L., and Bartkowicz, T. J., "Extraction of Modal Parameters From Spacecraft Flight Data,“ Submitted to the 49 ${ }^{\text {th }}$ International Modal Analysis Conference, Jacksonville, FL, Feb. 2011,13 pp.

${ }^{14}$ Templeton, J.D., Buehrle, R. D., and Gaspar, J. L., “Ares I-X Launch Vehicle Modal Test Measurements and Data Quality Assessments,” Proc. 48 ${ }^{\text {th }}$ International Modal Analysis Conference, Paper No. 232, Jacksonville, FL, Feb. 2010.

${ }^{15}$ Ewins, D. J., Modal Testing: Theory and Practice, New York: Wiley: 1984.

${ }^{16}$ Decoursey, R., “Ares I-X Technical Analysis Report: Vehicle Sequencing Ares I-X Flight Test,” NASA Report No. A1XTAR-SYS0007, Feb. 2010.

${ }^{17}$ Allemang, R. J., “The Modal Assurance Criterion - Twenty Years of Use and Abuse”, Sound \& Vibration, Aug. 2003, pp. 14-21.

${ }^{18}$ CxP 70137, Rev. B., “Constellation Program Structural Loads Control Plan,” NASA, Sep. 2009. 